Evaporation Control Research, 1959-60

GEOLOGICAL SURVEY WATER-SUPPLY PAPER 1692

Prepared in cooperation with the Texas Department of Agriculture, and in collaboration with Southwest Research Institute and Southwest Agricultural Institute

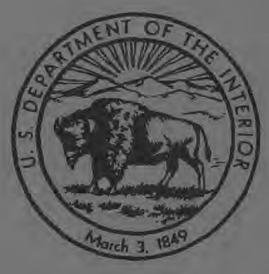




\section{Evaporation Control Research, 1959-60}

By GORDON E. KOBERG, ROBERT R. CRUSE, and CHARLES L. SHREWSBURY

GEOLOGICAL SURVEY WATER-SUPPLY PAPER 1692

Prepared in cooperation with the Texas Department of Agriculture, and in collaboration with Southwest Research Institute and Southwest Agricultural Institute

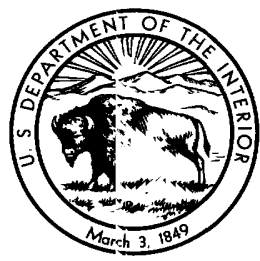




\section{UNITED STATES DEPARTMENT OF THE INTERIOR}

STEWART L. UDALL, Secretary

\section{GEOLOGICAL SURVEY}

Thomas B. Nolan, Director

The U.S. Geological Survey Library has cataloged this publication as follows :

\section{U.S. Geological Survey.}

Evaporation control research, 1955/58Washington, U.S. Govt. Print. Off., 1960-

v. illus., diagrs., tables. $24 \mathrm{~cm}$. (Its Water-supply paper 1480, 1692 Prepared in cooperation with the Southwest Research Ins'itute and other agencies.

1. Evaporation control. I. Title. (Series) 


\section{CONTENTS}

\begin{tabular}{|c|c|}
\hline \multirow{2}{*}{\multicolumn{2}{|c|}{ Ahatrant }} \\
\hline & \\
\hline Introduction & \\
\hline Cheoretical considerations & \\
\hline Film resistance to evaporation & \\
\hline Theory of spreading & \\
\hline Laboratory studies & \\
\hline Experimental & 6 \\
\hline Laboratory conclusions & 13 \\
\hline Field studies_. & 14 \\
\hline Description of test sites & 14 \\
\hline Evaluation method & 15 \\
\hline 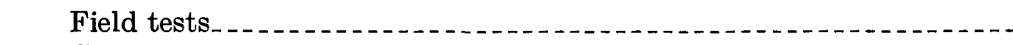 & 17 \\
\hline Conclusions on field tests & 37 \\
\hline Suggestions for future work & 39 \\
\hline Laboratory studies & 39 \\
\hline Field studies & 40 \\
\hline ferences cited & 42 \\
\hline $\begin{array}{c}-1 \\
-1\end{array}$ & 55 \\
\hline
\end{tabular}

\section{ILLUSTRATIONS}

Figure 1. The orientation of alkanols on the surface of the water...-.-

2. A comparison of oil-in-water and water-in-oil dispersions and the orientation of the emulsifying agent molecules....-

3. A comparison of photomicrographs of $\mathrm{O} / \mathrm{W}$ and $\mathrm{W} / \mathrm{O}$ type dispersions.

4. A schematic diagram for the process of coacervation......-

5. Instrumentation raft showing anemometer and shelter for

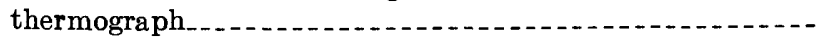

6. Relation between reservoir change in stage $(\Delta H)$ and th? product $u \Delta e$ for Pinta Valle stock tank .............

7. Location of eight dispensers at Briones stock tank

8. An aerosol-ty pe field dispenser

9. Diagram of electrical circuit used to control the aerosol-type dispenser at Briones stock tank . . . . . . .

10. A gravity-type dispenser

11. Diagram of electrical circuit used to control the gravity-typ? dispenser at Briones stock tank

12. Drip dispenser at Zimmerman stock tank

13. Location of drip dispensers around Zimmerman stock tank ...- 
Figdre 14. Sketch of wind-controlled dispenser.
15. Location of wind-controlled dispensers of Pinta Valle stock tank

16. Floating barrier.

17. Wind-controlled dispensers at Carlos stock tank _...... 29

18. Location of seven dispensers at Essar Ranch Lake _..._._. 34

19. A band of film across lake.... 35

\section{TABLES}

TABLE 1. Emulsifiers available for evaluation with water evaporation

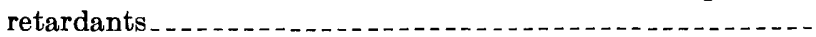

2. Water-in-oil emulsions using 250 grams of dodecanol as the oil

3. Oil-in-water dispersions of alkanols

4. Water-in-oil dispersions of hexadecanol and octadecanol....

5. Dispersions containing 11 to 20 percent octadecanol (Lorol 28) based on water, and using glyceryl monostearate (self-emulsifying) as the dispersing agent.............

6. Dispersions of octadecanol containing varying amounts of glyceryl monostearate (self-emulsifying) as the dispersing agent . . - 


\title{
EVAPORATION CONTROL RESEARCH, 1959-60
}

\author{
By Gordon E. Koberg, ${ }^{1}$ Robert R. Cruse, ${ }^{2}$ and Charles L. \\ SHREWSBURY ${ }^{3}$
}

\begin{abstract}
Two hundred and forty-five dispersions of long-chain alkanols were formulated by using various emulsifiers and alkanols. The dispensing and spreading ability of each of these formulations was tested. The most promising emulsifier that could be used with any of the alkanols was glyceryl monostearate (self-emulsifying). However, the concentration of the alkanol in the dispersion form varied somewhat with the length of the carbon chain. A maximum concentration of $\mathbf{1 6}$ percent was obtained using the longer chain alkanols in the dispersion form without losing any of the properties of a fluid.

Nine field tests were undertaken on small stock tanks. The retardant materials used in these tests were dodecanol, hexadecanol, and octadecanol. These materials were applied in either liquid or dispersion form. Four types of dispensing equipment were tested. The first type used a pressure syster which sprayed a liquid onto the surface of the water. An anemometer and wind-controlled vane, operated by an electrical system, determined the length $\varepsilon$ nd frequency of application. The second type was similar to the first except that gravity was utilized to force the liquid onto the surface. The third type used a drip system with rates of about 10 drops per minute. The fourth type used a gravity feed and a wind-controlled valve which allowed the dispersion naterial to flow onto the surface of the water when the wind was in the proper direction.

In the field tests, the best reduction in evaporation was obtained using octadecanol in dispersion form and dispensed with the wind-controlled valve and gravity feed system. The maximum reduction in evaporation for a 2-week period was 27 percent. However, the economics of suppressing evaroration from stock tanks is questionable because of the short travel time across the tank by the film.

There are still many problems unsolved. Some of these can be resolved in the laboratory whereas others can be resolved only in the field. Some of the more serious problems are the effect of impurities in the alkanols; the rate of cooling of the alkanol from a liquid to a solid state; the effect of the film on the exchange of water molecules between the air and water; whether the film remains effective in suppressing evaporation for any rate of movement downwind; and the possible use of dodecanol and eicosanol as suppressants.
\end{abstract}

\footnotetext{
1 U.S. Geol. Survey.

2 Southwest Research Institute.

s Southwest Agricultural Institute.
} 


\section{INTRODUCTION}

The purpose of this investigation was to develop a prectical, safe, and effective method of treating the surface of a water reservoir with a monomolecular chemical film to reduce loss of water by evaporation.

These objectives are the same as those of an earlier investigation reported by Cruse and Harbeck (1960).

This report describes the laboratory and field investigations during the period 1959-60. The emphasis in the laboratory investigations was to formulate and test various dispersions of alkanol for their spreading ability and ease of dispensing. The field investigations were made to evaluate the success of the various formulations in reducing evaporation in which the formulations were dispensed from several types of dispersions. These investigations were made in cooperation with the Texas Department of Agriculture, and in collaboration with the Southwest Research Institute and Southwest Agricultural Institute, both at San Antonio, Tex.

The loss of water by evaporation from lakes and reservoirs is a serious problem in areas where the limited water supply cannot meet the demands of the users. A possible method of increasing th is supply is by conserving the water that would normally be lost by evaporation. Rideal (1925) demonstrated in the laboratory that water surfaces covered with monolayers of fatty acid had slower evapcration rates than those without the fatty acid. Since then, other workers have confirmed his work, but have indicated that greater reductions can be obtained from monolayers of the longer chain alkanols.

The first application of monolayers to open surfaces of water was made in the early 1940's but the results were inconclusive. In 1952, Mansfield (1955) began field testing monolayers in Australia and reported that evaporation rates were reduced by as much as 30 percent. Thus encouraged, investigators in this country began field studies in 1955. Results to date have not been very encouraging becruse reliable methods for applying and maintaining a monolayer on sn open surface of water have not been developed. The greatest difficulty is that the problems in field application are not always clearly understood. Most investigators therefore have used trial and error mathods in an attempt to develop satisfactory techniques.

Some investigators have considered the possible use of monolayers to reduce losses from plant transpiration and evaporation from soils. Preliminary reports have indicated that this may be feasible. Such studies, however, are not within the scope of this report which deals only with the application of monolayers to open surfaces of water. 


\section{THEORETICAL CONSIDERATIONS}

\section{FILM RESISTANCE TO EVAPORATION}

It has been demonstrated through laboratory experiments that when a monomolecular film is formed on the surface of the water from alkanols, evaporation is thereby reduced. However, the conditions under which these experiments are conducted never simulate field conditions completely. Even if actual field conditions were simulated, the results may be questionable as each experiment would be very difficult to reproduce because of the many meteorological variables.

According to Rosano and La Mer (1956), three sets of conditions have been employed in the laboratory to measure the rate of eraporation of water through films. The conditions are: (1) A current of air is passed over the surface; (2) the air above the surface is free of convection currents; (3) a partial vacuum is created above the surface. Condition 1 will generally approximate field conditions but does not take into account the continual movement of the film downwind. Condition 2 will only approximate field conditions for special periods when the atmosphere is stable and wind speeds are very low. Condition 3 will never exist. Therefore, the laboratory results of determining the effectiveness of the film in suppressing evaporation are not applicable for general field conditions, but are applicable only for specific conditions. However, these results serve a useful purpose when comparing one type of film with another. Also, laboratory tests define the effectiveness of the film in relation to temperature and film pressure.

The laboratory results from condition 3, according to Farkins (1952), should give the best results for retarding evaporation. $\mathrm{He}$ reasoned that when air is present over the surface nearly every water molecule which succeeds in moving out of the surface moves 1 n.ck in again. But this is not true when the evaporation into a vacuum takes place-a vacuum eliminates or minimizes the effect of the film in retarding the return movement of molecules from the air to the water.

The effect of the film in retarding the movement of water molecules from the air through the film has never been considered. It is possible that the film may have more retarding effect to the movement of molecules from the air to the water than from the reverse direction locause of the orientation of the alkanol molecules. The alkanol molecules are oriented, according to the theory of spreading (Harkins, 1952), with the polar end toward the water and the nonpolar end toward the air as shown in figure 1 . The nonpolar end would repel water molecules from the air while the polar end would attract water molecules. For this reason the resistance of the film should be more effective to 


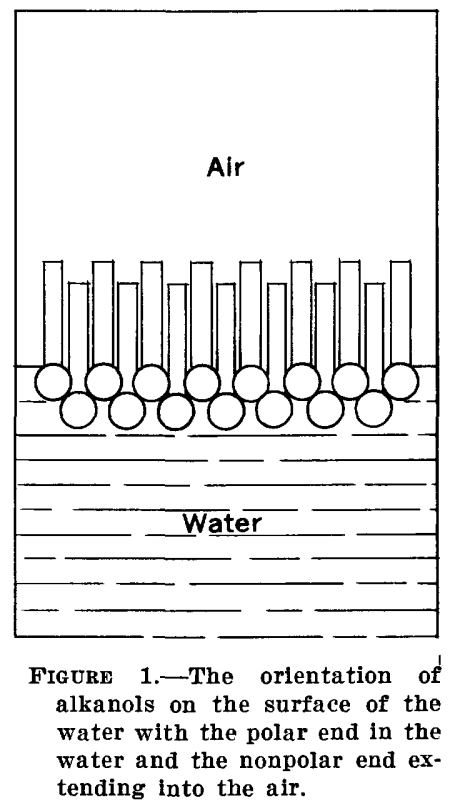

the movement of water molecules from the air to the water, especially at low film compression where the resistance of the film is not very effective in retarding the movement of molecules from the water to the air. Laboratory experiments are needed to determine whether the film retards the movement of water molecules from the air to the water under different conditions of humidity and surface compression.

If this theory is correct, the effect of the film in the field under low film pressures and high humidities would be to increase the evaporation rate. Some field tests have indicated this to be true, but the data were not conclusive enough to confirm the theory. Of course, linder high film pressures the film would be effective in retarding evaporation under most humidity conditions.

McArthur and Durham (1957) in their laboratory worl- have indicated that the most effective film should be at least 5 molecules thick. The measurement of the thickness is based on the amount of dosage applied to the surface of the water. As the measurement of thickness is based on theoretical considerations and is not substantiated by direct measurements, the work may be some what questionable.

In the field there is no way, as yet, of determining the thickness of the film. It is believed by some investigators that the film thickness is 1 molecule thick while others believe it to be 1 or several molecules thick. Photographs of the film in the field have indicated that the reflection of light from the film for some areas seems to be different from others. This change in light reflection could be caused by the 
variation in thickness of the film. However, it is also possible that surface pressure may have some effect on the reflected light.

\section{THEORY OF SPREADING}

According to Harkins (1952), films may form upon the surface of a liquid or a solid either by condensation from a vapor (adsorption) or by the liquid of a solid body, which floats upon $o^{n}$ is in contact with the surface. Film formation, then, will occur only at the surface of the water and around the perimeter of the solid material forming the film. For rapid film formation, the alkanol when placed on the surface of the water should remain and spresd out over the water surface, creating a large perimeter.

In order to maintain film coverage in the field, where the film material is applied at a point source, film formation should be as repid as possible in order to replenish the loss of film by the wind. According to McArthur and Durham (1957), a moderate wind moves th ? film in a downward dtrection at a rate of $14 \mathrm{fpm}$ (feet per minute). At this rate 14 square feet of film would be removed from the water surface for every lineal foot along the upwind shoreline. Therefore, when a film-forming material is placed on the surface of the water at a point source it must remain and break up rapidly to form many small air-water perimeters for film generation; consequently, the laboratory work in this investigation has been devoted to finding the smallest particle size of the solid material that can be preserved and easily dispensed from an unattended point source.

\section{LABORATORY STUDIES}

The field application, there are three possible methods of ap olying the alkanols in a small particle size: (1) Use of a dry powder, (2) use of the powder dispersed in a liquid and applied as a fluid, and (3) use of a solvent that will dissolve the alkanol. Since methods 1 and 3 were being tried by other investigators, method 2 was selected for testing. Furthermore, it was considered to be the most economical method of application.

If an alkanol is ground to a fine powder and mixed with water, the powder will remain dispersed as long as mixing occurs; however, the powder and water will begin to separate when mixing stops. This is not desirable for field use when the force of gravity is used to move the liquid. In this case, continual mixing would be required to keep the powder dispersed so that a uniform mixture could be disnensed when needed. 
The use of dispersions or emulsions seem to be the most promising to overcome the problem of separation, and the emphasis has been on finding a dispersion that will not separate, that will flow as a liquid and that will break up immediately when placed on the water surface.

Two general types of dispersions are described in the literature (Becher, 1955, 1957). These are oil-in-water $(\mathrm{O} / \mathrm{W})$ and water-inoil $(\mathrm{W} / \mathrm{O})$. Both types of dispersion were studied in the course of this work. As an evaporation retardant, the water-in-oil dispersions should be superior to the oil-in-water dispersions. Because the formation of a monomolecular evaporation-retardant film takes place only at the surface of the reservoir, the water-in-oil dispersion, having the oil as the continuous, or external, phase would expose the evaporation retardant (the oil phase in this case) to the surface of the reservoir immediately. When an oil-in-water dispersion is used, the water, which is the continuous phase, must be dispersed before the surface phenomenon of spreading-the-oil phase can occur. This is illustrated in figure 2.

A secondary, but nonetheless important criterion in selecting the dispersing agents for any recommended formulation, is the toxicity of the dispersing agent itself. The U.S. Public Health Service (Cincinnati, Ohio) has granted unqualified clearance to the use of 1-hexadecanol and 1-octadecanol as evaporation retardants. No such clearance has been granted any of the dispersing agents when formulated with the evaporation retardants. Therefore, although all types of dispersing agents were considered, attempts were mada to choose a dispersing agent for the final formulation that would not be considered toxic by either the U.S. Public Health Service or the U.S. Food and Drug Administration on the basis of prior food use or other criteria. The dispersing agents that were considered and are available for experimentation are listed in table 1.

\section{EXPERIMENTAL}

The first of several dispersion and emulsion formulatiors prepared in the laboratory were the $\mathrm{W} / \mathrm{O}$ type. These dispersions were prepared by heating 250 grams of dodecanol (Lorol 7) to about $80^{\circ} \mathrm{C}$ in a 2 -liter beaker. In a separate beaker, $250 \mathrm{ml}$ of water was heated to $80^{\circ} \mathrm{C}$. The emulsifying agent was added to the oil phase, or in this case to the dodecanol. The water was added to the oil while still hot, and stirred vigorously until cool. W/O dispersion* prepared using dodecanol are summarized in table 2. All these dispersions separated or formed pastes which are not desirable for field use. 


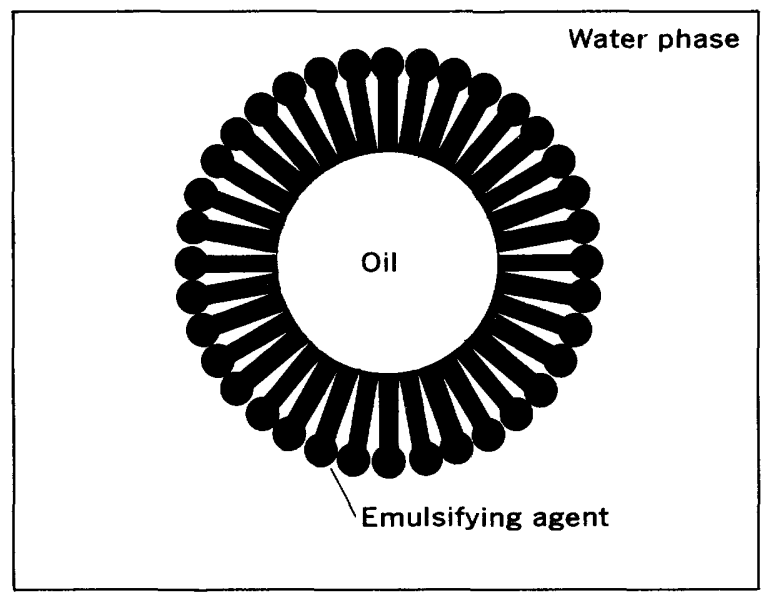

OIL-IN-WATER

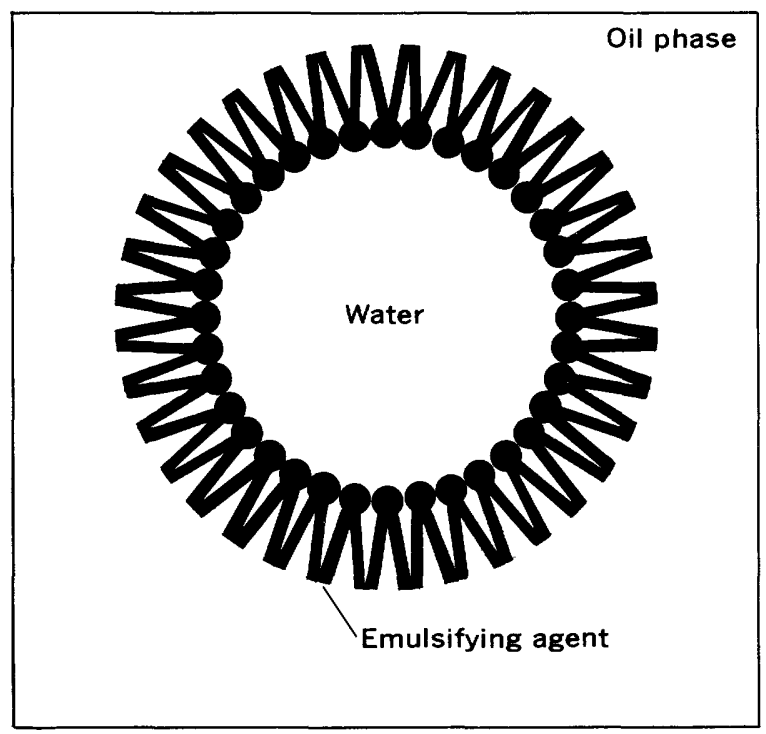

WATER-IN-OIL

FIGURE 2.-A comparison of the oil-in-water and the waterin-oil dispersions and the orientation of the emulsifying agent molecules. 
In view of the high viscosity of the dispersions produced by the procedure using dodecanol, emphasis was placed for a time on the preparation of $\mathrm{O} / \mathrm{W}$ type dispersions. These were prepared by heating the water ( $500 \mathrm{ml}$ to 1 liter) to $80^{\circ} \mathrm{C}$, adding the emulsifying agent, and then adding the molten alkanol. Vigorous stirring was maintained until the mixture was cold. An alternative procedure, with which it was somewhat easier to work, involved loating the water and the alkanol together until the alkanol had melted. The mixture was placed under a high-speed stirrer and the emulsifying agent was added. Stirring was continued until the mixture was cold. The procedures proved to be interchangeable. Data on preparation of $\mathrm{O} / \mathrm{W}$ type dispersions are summarized in table 3, with remarks concerning separation and whether the dispersions were liquid, paste, or gelatinous. The $\mathrm{W} / \mathrm{O}$ type dispersions in table 3 were $\mathrm{rr}$ ostly pasty or gelatinous. When the paste or gelatinous material is placed on the surface of the water, it does not break up rapidly; consequently, water-in-oil dispersions were again investigated. Becher (1955) indicates that $\mathrm{W} / \mathrm{O}$ type dispersions are best prepared using greater than 50 percent oil in their formulation. A previous experinent in this study, using the self-emulsifying glyceryl monostearate as the dispersing agent and equal amounts of dodecanol and water, yielded a $\mathrm{W} / \mathrm{O}$ type dispersion with a pasty consistency similar to that of mayonnaise. Becher (1957) also indicated, contrary to the above statement, that under some circumstances it was possible to prepare W/O type dispersions containing greater than 50 percent water by giving careful attention to the following details: (1) Adding the water to the oil phase with agitation, and (2) making sure that the sides of the reaction vessel were coated with the continuous phase (in this case the oil phase would be alcohol). It seemed likely, then, that $W / O$ type dispersions would be possible if hot water were added to an agitated oil and dispersant mixture with the oil phase being on the sides of the reaction vessel as the water is being added. The procedure involved melting the desired amount of alcohol together with the dispersing agent in the amount of 10 percent by weight of the alcohol. The mixture of the two was heated above the melting point of the alcohol and stirred vigorously. Next, the desired amount of hot water (about $70^{\circ}$ to $80^{\circ} \mathrm{C}$ ) was added, and stirring was continued until the mixture cooled.

Data on W/O type dispersions prepared by this procedure are presented in table 4 . Because of the pasty appearance of the first four dispersions (255-258) as well as the emulsions of dodecanol previously prepared, a series of dispersions using hexadecanol with glyceryl monostearate (self-emulsifying) as the dispersing agent was prepared, 
and larger amounts of water were used in order to ascertain whether the use of more water would cause an inversion to an $\mathrm{O} / \mathrm{W}$ type dispersion. Inversion did not seem to occur. Dispersions 261 through 264 were those prepared in this particular series. Dispersion 264 proved to be very promising, from the standpoint of breakup, spreading rate, and viscosity characteristics. Both the quantities of materials and the order and method of mixing employed in this improved procedure were used in subsequent preparations of $\mathrm{W} / \mathrm{O}$ type dispersions. By this procedure, W/O type dispersions containing concentrations of up to 16 percent by weight of solid octadecanol, as shown in table 5, can be obtained without sacrificing the viscosity of the liquid dispersion. With $\mathrm{O} / \mathrm{W}$ type dispersions, 2.5 percent by weight of octadecanol appears to be a desirable average, with 4 percent a maximum in hot weather. Greater than 4 percent hexadecanol or octadecanol renders the dispersion too viscous for easy hanc'ling.

To determine the percentages of hexadecanol that can be used in W/O type dispersions, a series of three dispersions was prepared. Each of these utilized 1 liter of water; 100, 150, and 170 grams of hexadecanol (Lorol 24) respectively; and 10 percent by weight of glyceryl monostearate (self-emulsifying), based on the amount of hexadecanol. All three dispersions proved undesirably thick for field use. To get some idea of the numerical value of the viscosity, the dispersions were placed at room temperature (about $82^{\circ} \mathrm{F}$ ) on a Fann $\mathrm{V}-\mathrm{G}$ viscosimeter. The 10 and 15 percent hexadecanol dispersions prepared as described above were used. Results were as follows: 10percent dispersion, viscosity 110 centipoises; and 15-percent dispersion, viscosity 93.5 centipoises.

The dispersions are obviously non-Newtonian fluids, and hence the value of the viscosity in centipoises may not be significant in terms of the ability of the dispersion to flow through the dispensers.

The use of W/O type dispersions of hexadecanol in the field is limited to 8-percent concentrations of hexadecanol as compared with 16-percent concentrations of octadecanol. The reason for this is unknown. The only apparent difference between the two alkanols is that octadecanol has a longer chain than hexadecanol, but this does not seem to be a likely reason for using different amounts of concentrates. In view of this uncertainty, a short set of experimer ts were conducted to ascertain whether an eicosanol or a docosanol, both of which have longer carbon chains than octadecanol, would be usable in a dispersion. Previous work had indicated that eicosanol and docosanol would not spread adequately. However, it was felt that a W/O. dispersion might add enough spreading ability to the material, owing to the surfactant (dispersant) present, to cause a change in the per- 
formance of these alkanols and thus produce a thicker monomolecular layer. Using the same mixing procedure that previously used for the W/O type dispersions, the following dispersions were prepared with these materials:

Alkanol A

(Adol 60-80 percent 1-docosanol, 12 percent

1-eicosanol, and 8 percent 1-octadecanol) - 97 grams

Glycervl monostearate -9.7 grams

Water-970 grams

Alkanol B

(Adol 67-25 percent 1-docosanol, 30 percent

1-eicosanol, 30 percent 1-octadecanol, 15 percent

1-hexadecanol) -93 grams

Glyceryl monostearate -9.3 grams

Water-930 grams

Both the $\mathrm{A}$ and the $\mathrm{B}$ dispersions were stable and quite fluid. A field test of the spreading rate indicated that both dispersions were comparable to that of octadecanol.

In making up these dispersions for test purposes, the questions arose as to the amount of dispersing agent needed to disperse the water or alkanol in the dispersed phase and whether the amount of dispersing agent had any effect on the viscosity of the dispersion. As a result, several sets of dispersions were prepared to resolve these questions. The first set (test No. 286-291) utilized 100 grams of octadecanol (Lorol 28) and amounts of glyceryl monostearate (self-emulsifying) varying from 10 to 15 percent of the amount of octaderanol used. The results are presented in table 6 . No significant differences in viscosity were noted amoung the varying concentrations of glyceryl monostearate.

A second set of tests (test No. 292-294) utilized 10 grams of glyceryl monostearate to 110,120 and 130 grams, respectively, of octadecanol (Lorol 28) in 1 liter of water. All separated after 48 hours of standing, indicating that the proportionate amount of emulsifier with respect to the alkanol should be 10 percent.

At first the method of cooling was to place the mixing ressel in the air at room temperature and stir the mixture until it cooled. If a jacket of cold water is placed around the vessel and stirring is continued, the mixture, of course, is cooled at a faster rate. This increased rate of cooling seems to lower the viscosity of the dispersion material and also improve the spreading characteristics. When some of these rapidly cooled dispersions were examined under the microscope, a crystallinelike structure was observed on the solidif 'ad alkanol. There was no indication of such a structure when dispersion material cooled at a slower rate was examined. However, time did not permit 

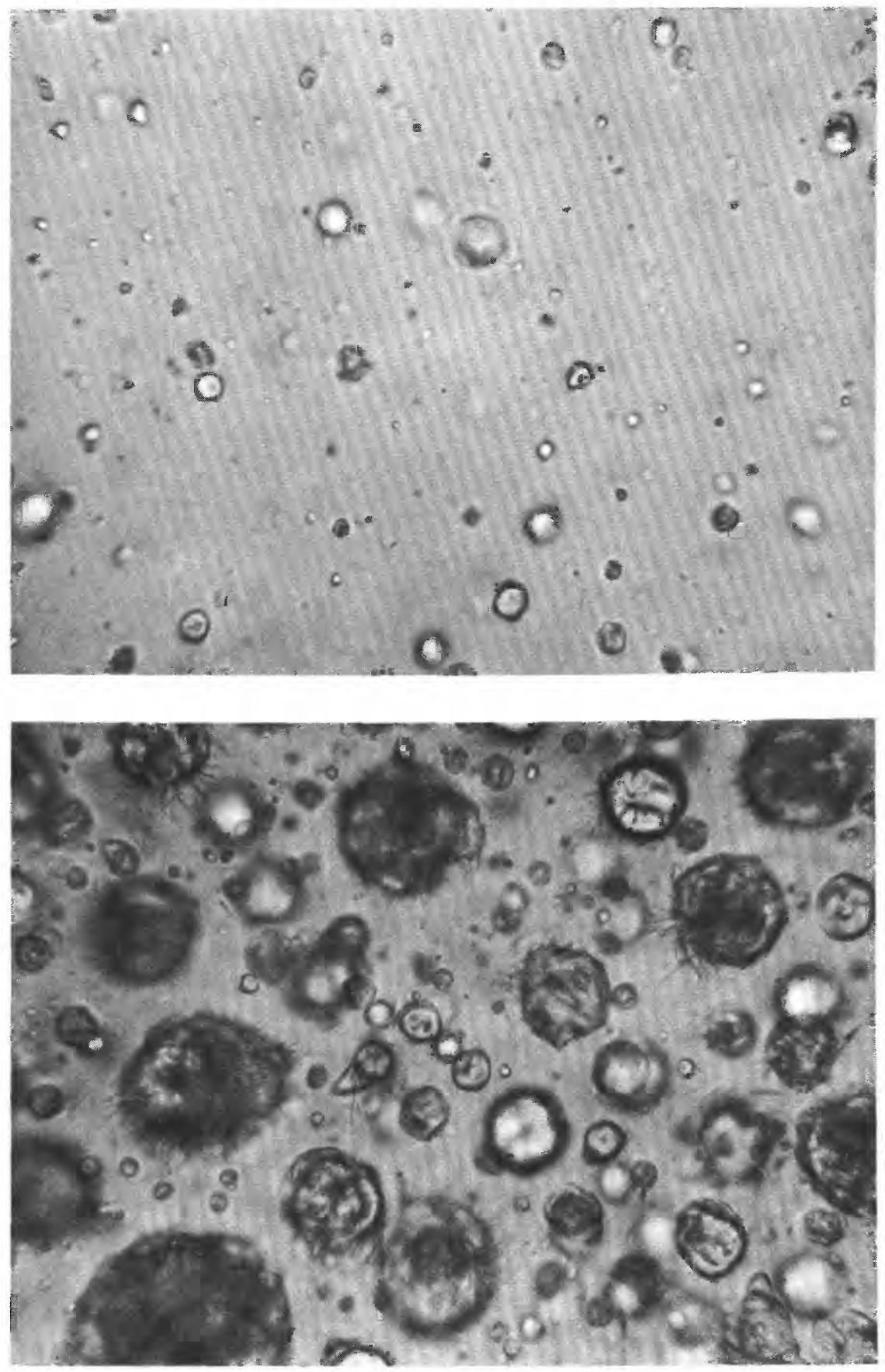

Figure 3.-A comparison of photomicrographs of 2.5-percent $O / W$, above; and 10-percent W/O type dispersions, below. $\times 430$. Photomicrographs by Southwest Research Institute. 
further work on this phenomenon, although it is apparent that more laboratory work is needed.

The W/O dispersions prepared by the Becher (1957) procedure, which requires the use of only a small amount of oil, have been quite fluid in nature and opaque and milky white in appearance. The $\mathrm{O} / \mathrm{W}$ type dispersions on the other hand, have been somewhat gelatinous and translucent. Also, there is a distinct difference in the viscosity of the two types of materials. These differences between the $\mathrm{O} / \mathrm{W}$ and the W/O dispersions were generally accepted during the course of this investigation as adequate evidence of the true nature of the dispersions. In an attempt to confirm this, photomicrographs of the various dispersions were made. Several 2.5-percent $\mathrm{O} / \mathrm{W}$ type dispersions and 10-percent $W / O$ type dispersions were prepared and photographed on microscope slides at $\times 100$ and $\times 430$. Representative photomicrographs are shown in figure 3. Because the appearance of the particles under the microscope are not significantly different, there is some doubt as to whether the W/O type dispersion has the alcohol as the continuous phase. However, a dispersion using an oilsoluble blue dye, which was incorporated into the melted hexadecanol, was prepared. Observation of this dispersion under the microscope indicated the presence of some discreet particles of hexadecanol surrounding an aqueous nucleus. The contrast did not show up on the black and white photograph.

Although the photomicrographs of the two types of dispersions do not indicate that there is a difference in the viscosity of the two materials, a possible explanation of this difference based on microsopic observations, is that the molten alkanol first encapsulates a small amount of water, thereby forming a small spherical particle, perhaps 0.1 micron in diameter. On rapid cooling, these discreet particles are solidified and, because of their small size, become suspended in the excess water which is undoubtedly present. The fact that the particles are discreet and that they have the alkanol as the outer walls would account for the rapid spreading rate of the W/O type dispersions. In the case of the $\mathrm{O} / \mathrm{W}$ type dispersions it would be necessary for the water that formed the outer walls of the capsule to be dispersed in the reservoir before the surface of the hexadecanol particle would be available at the reservoir surface to spread and form a film.

Another possible explanation for the difference in viscosities of the two dispersions is the phenomenon of coacervation, as described by DeJong (1949). In coacervation, individual solvated particles collect and form a larger particle with several individual nuclei. One form of coacervation is illustrated in figure 4 . The makeup of the 


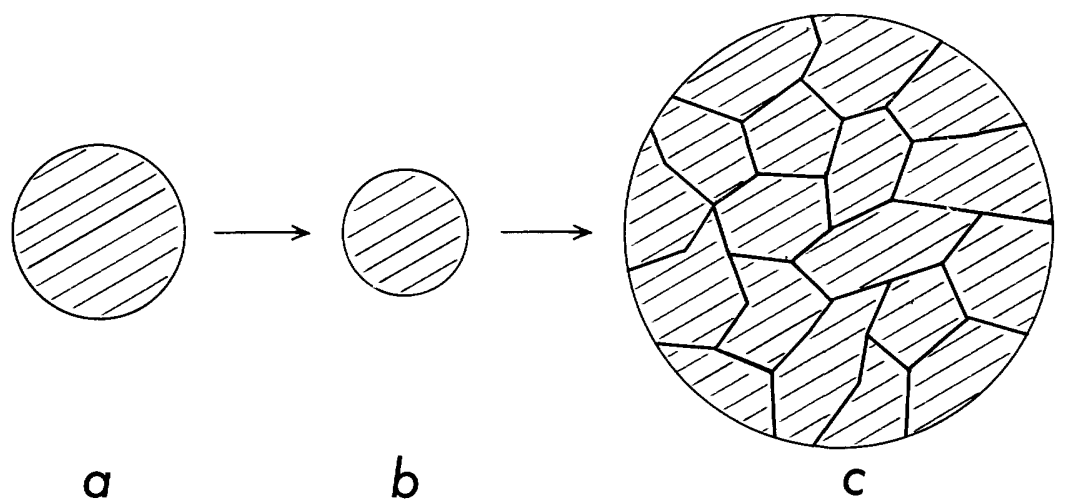

Figdre 4. - A schematic diagram for the process of coacervation. (a), The alkanol as a loosely built macromolecular particle in the original sol. (b), The macromolecular particles have become dense and tend to associate together. (c), In the coacervate there are mutually associated macromolecules that penetrate each other at least with their peripheral loops. The particles will form polygors with the strongest penetration at the sides of the polygon.

boundaries for the individual nuclei or the larger particles, which is a collection of the smaller nuclei, is not thoroughly understood. The authors are not familiar enough with the theory of coacervation to discuss it, but have presented it only as a possible source for further study.

It is apparent that the $\mathrm{W} / \mathrm{O}$ type dispersion borders between one that has a high degree of fluidity and one that is like a gelatinous paste. The type of dispersion formed and its stability will depend on the method of preparation, temperature, rate of cooling from a liquid to a solid, and possibly the addition of other chemicals. Before any wide use of the dispersion can be made, its form and stability in relation to these factors will certainly need further study.

As there is some doubt whether the $\mathrm{O} / \mathrm{W}$ type dispersion has the oil as the continuous phase, the W/O type terminology has ben used for this investigation because of the significant differences described in the preceding paragraph.

\section{LABORATORY CONCLUSIONS}

The selection of emulsifying agents or surfactants utilized in this investigation was based principally on their differences in molecular structure. Final evaluation was made by actually preparing dispersions using various alkanols. Several empirical systems, of which the Hydrophile-Lipophile Balance (HLB) (table 1) is the one most widely used, are available to facilitate the preliminary selection of emulsifying agents for certain uses, such as $\mathrm{W} / \mathrm{O}$ or $\mathrm{O} / \mathrm{W}$ type dispersions. The HLB system has been developed chiefly by tho Atlas 
Powder Company (Griffin, 1949, 1954) for application primarily to their products. Some expansion of the system was possible on the basis of the similarity of molecular structure of Atlas emulsifying agents with those of various competitors. As a result of this system, the choice of emulsifying agents was narrowed appreciably.

It is believed that the preferred emulsifying agent, glyceryl monostearate (self-emulsifying), is sufficiently nontoxic so that its use in evaporation suppression will be approved by the U.S. Public Health Service. However, specific clearance for the material has not been obtained. Adequate toxicity clearance should be obtained, of course, before the material can be used extensively. If proper clearance cannot be granted for the particular composition of glyceryl monostearate, other emulsifying agents that are nontoxic possibly could be used.

The development of the dispersion technique has led to the possible use of docosanol and eicosanol as evaporation retardants, but the toxicity of these alkanols is uncertain. In previous studies, these alkanols had very poor spreading rates, but when they were in the dispersed form, the spreading rate was as good as octadecanol or hexadecanol. The ability of docosanol and eicosanol to resist evaporation is uncertain, but it is believed that they may be superior to f axadecanol and octadecanol because of their longer chain.

In the laboratory experiments, the percentage of alkanols that can be dispersed in water or vice versa is equal to or greater than the amount that can be dissolved in a suitable solvent. Also, the material breaks up immediately upon being placed on the water surface, and its spreading characteristics are believed to be as good as those of solvents. The preparation of the dispersion is believed to be less costly than that of the solvent, and it also is considered to be much safer than solvents that are very volatile.

\section{FIELD STUDIES}

\section{DESCRIPTION OF TEST SITES}

Field studies were conducted on two 1-acre stock tanks 15 miles southeast of Laredo and two 1-acre stock tanks 12 miles northwest of Laredo, Tex. For reference purposes, the two tanks soutl aast of Laredo are called Briones and Zimmerman and the two northwest of Laredo are called Carlos and Pinta Valle. In addition to the tank tests, Essar Ranch Lake, a small 10-acre lake 10 miles vest of San Antonio, Tex., was used in the studies.

Rainfall and intermittent runoff from the small drainage basin above the tanks and lake contribute all of the water stored. There is no provision for releasing water in storage. Therefore, tha only out- 
flow from the tanks and lake are seepage and evaporation, plus the water consumed by the cattle and wildlife.

The material for constructing the dam for each tank is a gravelly clay that had been removed from the tank area. When the dam is completed, an excavated rectangular area, $1 / 2$ to 1 acre in size and approximately 15 feet deep, is left. The slope of the sides of this area are generally steep. During most of the year, all of the water stored in the tank is in the excavated area. Occasionally storage exceeds that which can be stored in the pit area, but only for short periods.

The dam for the Essar Ranch Lake is constructed with a heavy clay from the lake area. During the studies the level of the lake remained above that of the excavated area.

\section{EVALUATION METHOD}

In the field tests, the Harbeck and Koberg (1959) method was used to determine the effectiveness of the film in reducing evaporation. This method uses a combination of the energy-budget and masstransfer evaporation measurement techniques. For a specified period, the data that are needed to use this method consist of a measurement of the actual evaporation, the average wind speed, the average temperature of the water surface, and the average vapor pressure of the air. On the basis of these data, the savings in evaporation can be computed by substituting in the evaluation equation developed by Harbeck and Koberg (1959, p. 92). However, before the film is applied, a calibration period is needed to determine the coefficient for the masstransfer and conduction equations. The coefficient for the conduction equation is determined indirectly by the Bowen ratio. In this evaluation technique, it is assumed that for areas covered by film, a reduction in evaporation is offset by an immediate rise in temperature on the water surface, thus dissipating by radiation and conduction to the air the energy that would have been used by the evaporation. Later, it will be shown that the rise in temperature on the water surface takes place slowly and, as a result, energy is stored in the reservoir owing to the film.

The wind and temperature data needed for the evaluation technique are recorded in the following manner: The temperature of the surface of the water is recorded on a thermograph mounted on a raft which is located in the center of the tank or lake. Wind speeds are measured by an anemometer on the same raft on which the thermograph is mounted. After 10 miles of wind have moved past the anemometer, a tick is recorded on the margin of the thermograph chart. This is done by use of an electrical circuit and a solenoid. Figure 5 shows the raft with the instruments needed for the evaluation technique. 


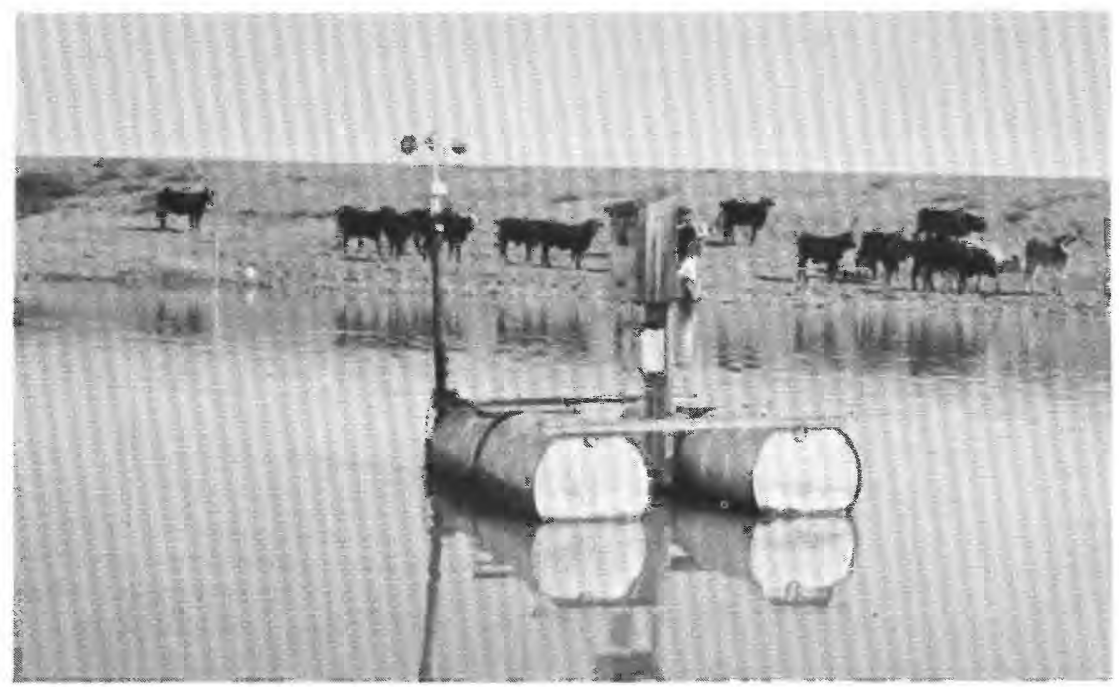

FigURe 5.- Instrument raft showing anemometer and shelter for thermograph.

The vapor pressure of the air is determined from data furnished by the U.S. Weather bureau. At the tanks near Laredo, the vapor pressure of the air is assumed to be the same as that observed by the Weather Bureau at the Laredo Air Force Base. At the lake near San Antonio, the vapor pressure of the air is the same as that observed by the Weather Bureau at the San Antonio International Airport.

The actual evaporation could not be measured directly; so it was determined by the following method: Each tank and lake was equipped with a continuous water-stage recorder. For a selected period when no surface inflow, outflow or rainfall occurred, a fall in stage was determined. This fall in stage resulted from seepage and evaporation and possibly some transpiration from vegetation which, in this study, would be included with seepage. The theory of the relation between fall in stage and certain meteorological parameters was first presented by Langbein and others (1951). For each selected period, average vapor pressure difference between the air at the surface of the water and the ambient air was computed $(u \Delta e)$. The vapor pressure of the air at the water surface was considered to be that of saturated air and at the temperature of the surface of the water. For each of these same selected periods, a corresponding change in stage of the tank or lake $(\Delta H)$ was determined.

With the computed products of $u \Delta e$ and the respective change in stage, a plot of these terms can be made on graph paper with $u \Delta e$ as the abscissa and $\Delta H$ as the ordinate. After a number of points are plotted, a straight line can be drawn through them as illustrated in 
figure 6. If this line is extended to the ordinate axis where $u \Delta e$ is zero, the intercept on the ordinate axis is the net seepage rate. When the product $u \Delta e$ is zero, evaporation is negligible as shown in an analysis by Marciano and Harbeck (1954). The slope of the line is the coefficient for the mass-transfer equation.

Once the net seepage rate is defined, the evaporation rate is easily determined by subtracting seepage from the change in stage. For small stock tanks, however, the seepage rate varies with season and stage so that frequent calibrations are needed to define this term. For these studies, the wind was measured approximately 2 meters above the water surface and, at this height, the mass-transfer coefficient generally remains constant for all seasons and stages (Harbeck, 1958).

In the field studies, the extent of film coverage has been determined mostly by visual observation. These observations are based on the fact that whenever the wind is blowing, the surface of the water will ripple. If a film is present, however, the ripples are suppressed, and the area coyered by the film can be identified. If no wind is present, an oil or dispersion test can be made. In this test a drop of oil or dispersion material is placed on the surface of the water, and if spreading takes place a film does not exist.

\section{FIELD TESTS}

The first field test for this report was made on the Briones stock pond in the spring of 1959. For this test, hexadecanol (20 percent by weight) dissolved in ethanol was used instead of the dispersion.

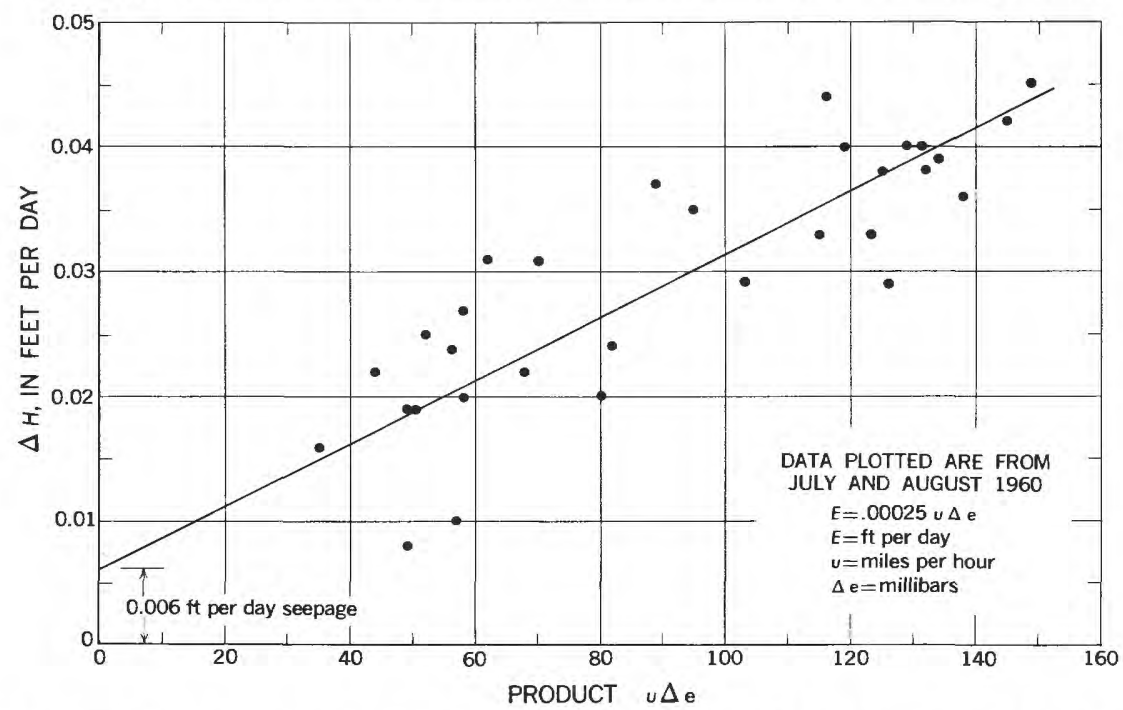

FIgURe 6.- Relation between reservoix change in stage $(\Delta H)$, and the product $u \Delta e$ for Pinta Valle stock tank. 
To dispense this liquid onto the surface of the water, a pressurized container, such as the commercial aerosol package, was used. Each container was filled with 75 percent by weight of the solution and 25 percent by weight of freon (F12), which was used as the propellant to force the solution out of the container through the valve. Each container, when filled, contained 4 pounds of material.

Eight aerosol-type dispensers were installed around the perimeter of the tank as shown in figure 7. These dispensers were about 75 feet apart. The valve on each container was opened and closed by an electrical solenoid. The valves, which were opened intermittently for about 1-second duration, were controlled by an anemometer and wind direction vane. Depending on the direction of the wind, 1 to 4 dispensers were activated by an anemometer switch after approximately $5 / 12$ miles of wind had moved past the anemometer. A field investigation of the dispenser is shown in figure 8 , and a schematic diagram of the electrical circuit which controlled the valve openings is shown in figure 9.

The field test of the dispenser started in February 1959 and continued through May 1959. During most of the time a considerable amount of electrical trouble was experienced by this system of dispensing. Some of the troubles were broken leads, poor electrical con-

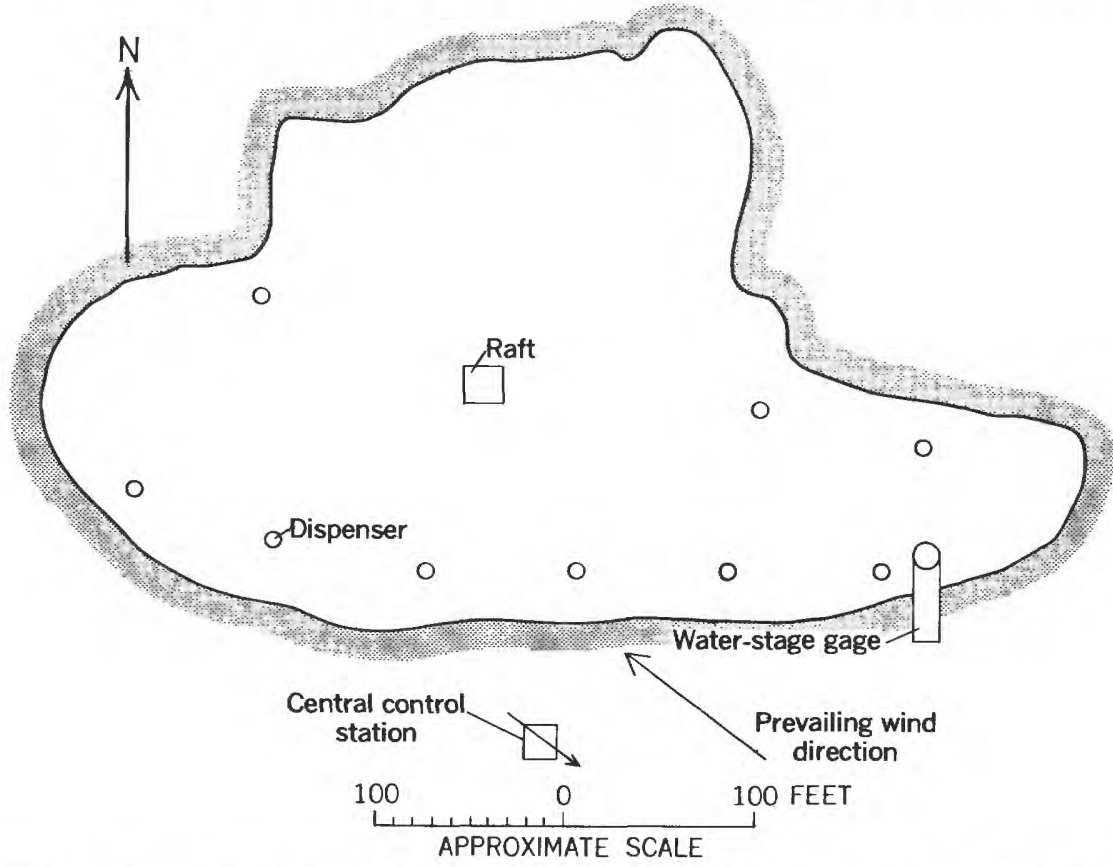

FrgURE 7.-A sketch map of the Briones stock tank showing the location of eight dispensers. 


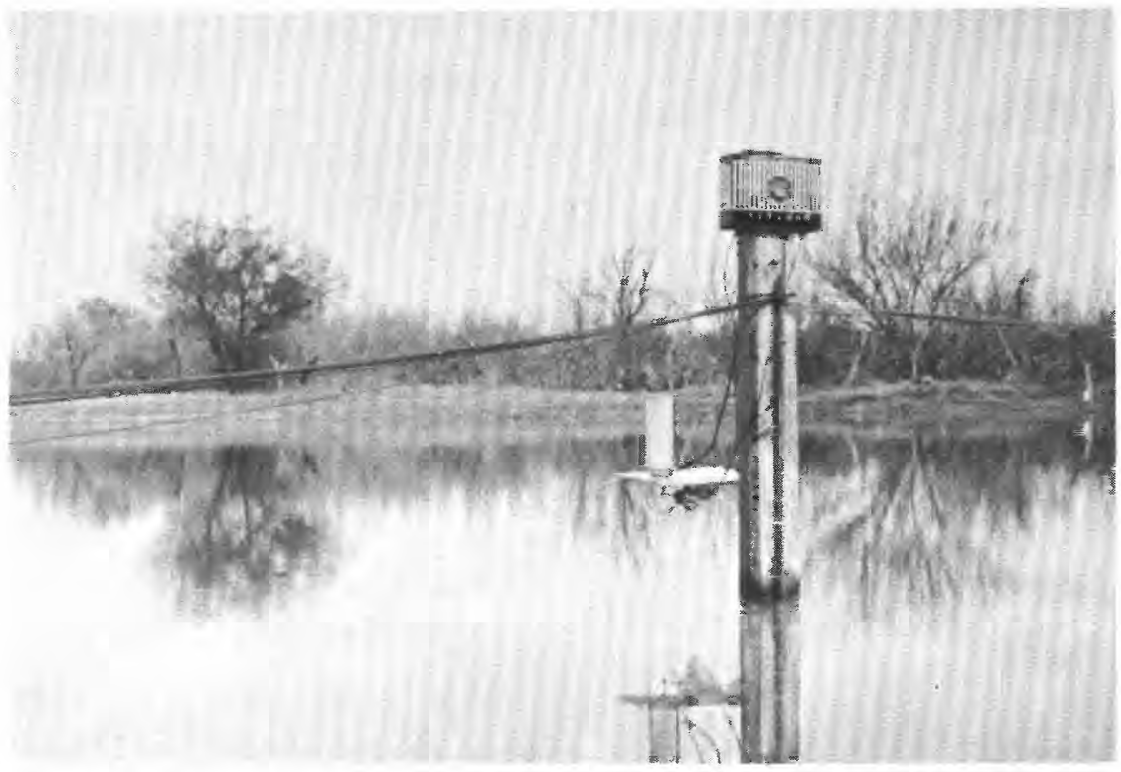

Figurn 8.-An aerosol-type field dispenser which sprays the liquid material onto the surface of the water whenever the valve is opened.

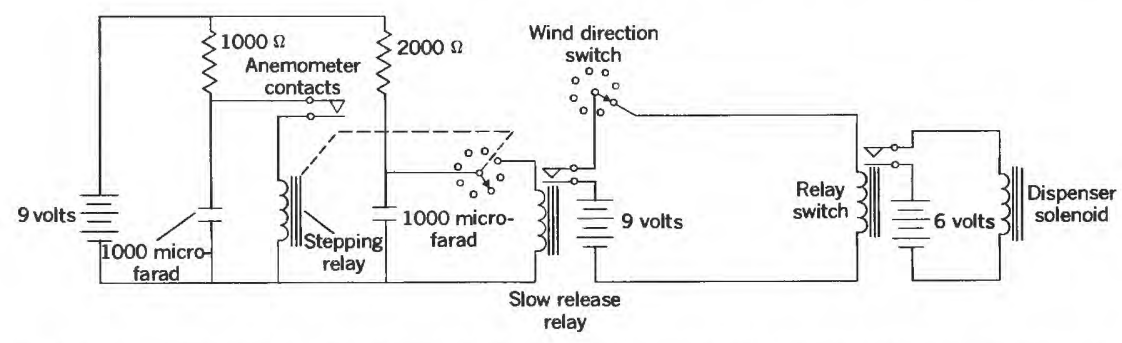

FIGURE 9.-Diagram of the electrical circuit used to control the aerosol-type dispenser at Briones stock tank near Laredo, Tex.

tacts due to corrosion, and solenoids freezing due to corrosion and solidified hexadecanol.

Most of the liquid material, when sprayed on the surface of the water, solidified into a thin lens of white material. The rate of spreading from this lens was not as rapid as that of the subsequent dispersion material. Consequently, the amount of film covered by each dispenser was limited to small circular areas about 20 feet in diameter, which remained constant as it moved downwind at approximately 10 feet per minute for wind speeds of 6 miles per hour. When the film reached the downwind shoreline, it generally moved onto the shore. During very light winds, however, the film remained on the surface and covered the entire area of the stock tanks. 
During most of the test, the savings in evaporation were negligible. However, one period of 18 days gave a computed saving of 5 percent. The amount of hexadecanol applied during this period was approximately one-half pound per day per acre. The average wind speed was 6.8 miles per hour, the average temperature of the surface of the water was $81^{\circ} \mathbf{F}$, and the evaporation was 4.2 inches.

Results of this test indicate that the method of controlling the dispensers was not reliable and that the method of application by use of aerosol dispensers did not lend itself to rapid film formation. Consequently, some of the solid hexadecanol was deposited on the downwind shoreline because the travel time across the tank was insufficient for all of the hexadecanol to be used for film formation.

It was noted at the termination of the test that a large amount of algae and aquatic plants were growing around most of the perimeter of the tank. This growth extended out from the shoreline about 6 feet. No other biological effects were observed.

Shortly after the termination of the first field test, the second test was started on the same tank. The number and location (fig. 7) of the dispensers and the electrical control system were the same as those of the previous test. In this test, dodecanol $\left(\mathrm{C}_{12}\right)$, which is a liquid above temperatures of $70^{\circ} \mathrm{F}$, was used as the film-forming material. The minimum temperature for the test period, June through August 1959 , was never below $70^{\circ} \mathbf{F}$ so that solidification did not occur.

The dispensers were modified so that the liquid could move from the container by force of gravity rather than by a propellant. A field installation of this dispenser (fig. 10) consists of a gallon can with a copper tube running from the bottom of the can to a small solenoid valve. When the solenoid is energized, the value opens"and the dodecanol flows onto the surface of the water. The valve is controlled in the same manner as the aerosol-type dispensers with certain modifications in the electrical circuit as shown in figure 11. The modifications did not eliminate any of the previous electrical malfunctions which continued through this test.

The dodecanol spread very well when applied to the surface of the water. The amount of surface area covered by the film varied with wind speed. Generally, with winds less than 7 miles per hour, about three-fourths of the surface area of the tank was covered. As the wind speed increased to 10 miles per hour, the film area decreased to about one-fourth.

The results of this test were not encouraging. Most of the time the savings were negligible. During one 24-day period, film reduced evaporation by 7 percent. The actual evaporation for this period was 5.7 inches, wind speed was 6.3 miles per hour, and the average tempera- 


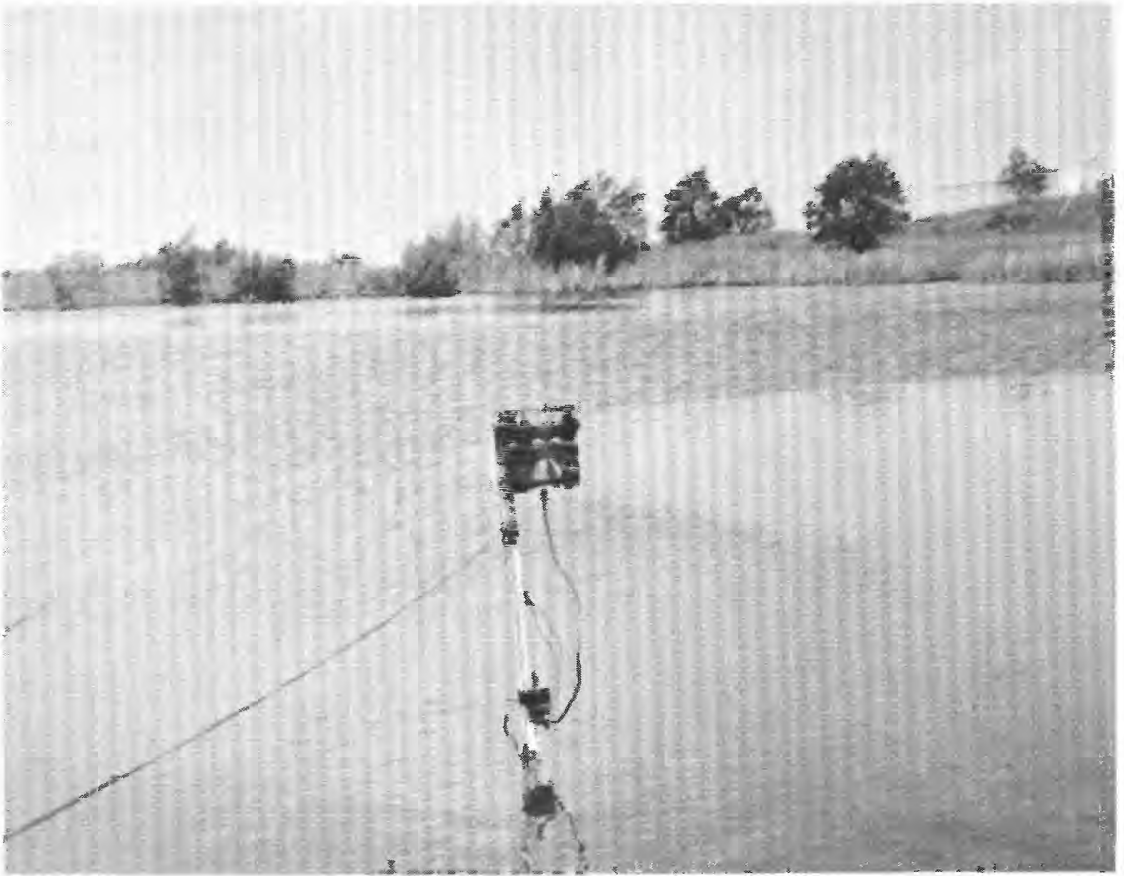

Figure 10.-A gravity-type dispenser showing the 1-gallon container at the top of the steel post and the solenoid valve at the bottom.

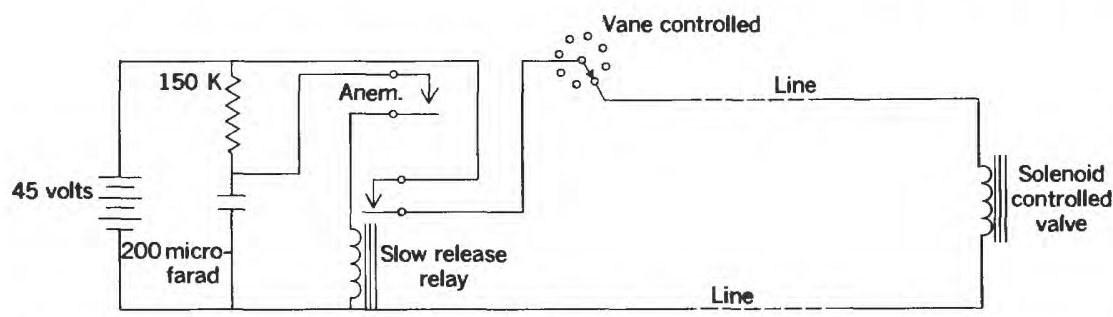

Figdrm 11.-Diagram of the electrical circuit used to control the gravity-type dispenser at Briones stock tank near Laredo, Tex.

ture of the surface of the water was $85^{\circ} \mathrm{F}$. Dodecanol was applied at the rate of 16 pounds per day per acre.

Although dodecanol spreads very well at temperatures above $70^{\circ} \mathrm{F}$, the test indicates that it has very little value as an evaporation retardant. The results of the earlier screening test (Cruse and Harbeck, 1960) had indicated that dodecanol containing significant amounts of hexadecanol and (or) octadecanol, was as good as hexadecanol. The reason for the low saving with good coverage is not known.

The large amount of aquatic growth that was present at the end of the first test remained through this test. The area covered by the 
growth did not change appreciably. No other biological effects were noticed even though a large amount of dodecanol was applied.

The third field test was made on the Zimmerman stock tank. This is the first test which utilized the dispersion as a method of applying the solid alkanol in a small partical size to the surface of the water. In this test, octadecanol was dispersed in water and stearic acid, and monoethanolamine was used as the emulsifier. The quantities of the various materials were as follows: 459 pounds of distilled water, 11.6 pounds of octadecanol, 1.15 pounds of stearic acid, and 0.26 pound of monoethanolamine. The method of mixing was the same as that of $\mathrm{O} / \mathrm{W}$ type dispersions described in the section on "Laboratory Studies."

To dispense the mixture, a simple equipment was used which continually dripped the dispersion material onto the surface of the water. The dispenser consisted of a gallon jug with a rubber stopper which had two holes through it. In these holes were inserted two capillary glass tubes having an inside diameter of 4 millimeters. One glass tube extended to the bottom of the jug so that when it was in an inverted position, air would be free to enter. The other glass tube was long enough to extend just through the rubber stopper. To regulate the rate of drip, a small wire was inserted in the short glass tube. The wire reduced the area of opening which in turn slowed down the drip rate. A field installation of the dripper is shown in figure 12. For this test, a drip rate of 10 drops per minute was assumed satisfactory. Because of the heterogeneity of the dispersion material, however, the drip rate varied considerably.

Twenty-eight dispensers were installed 20 feet apart around the perimeter of the Zimmerman stock tank as shown in figure 13. Each dispenser was installed about 8 feet from the shoreline and 2 feet above the surface of the water. Each drop of material would fall approximately 2 feet before impact with the surface of the water. After impact, the material remained as a drop and continued downward into the water for several inches, after which it would move back to the surface. What appeared on the surface, however, was only a small portion of the drop material, as most of it remained under the water surface. For spreading purposes this material is very poor as it remains in a drop and film formation is only along the perimeted of the air-water interface. If the material would break upon impact with the surface, the perimeter at the air-water interface would be increased considerably and this in turn would increase the spreading rate.

The field test was started near the end of June and continued through August 1959. During most of the time, the heterogeneity 


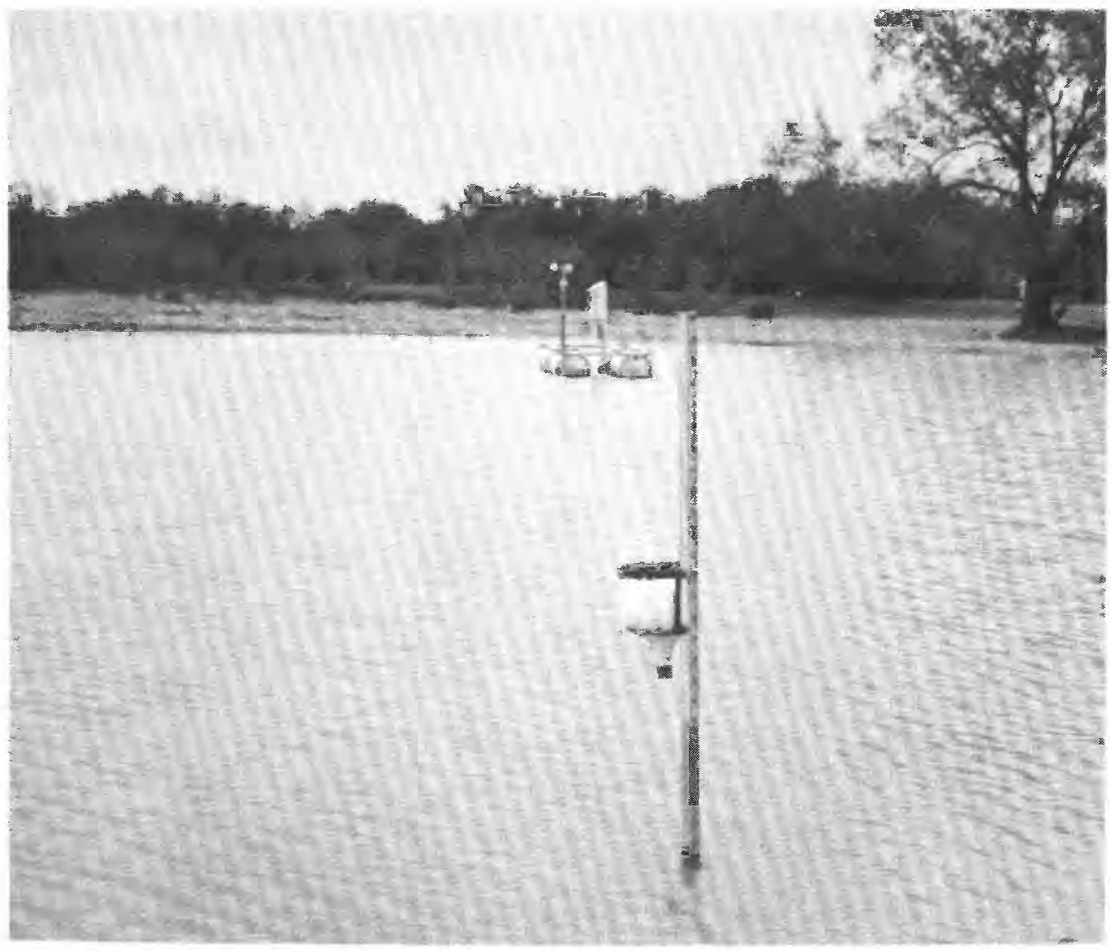

FIGURE 12.-A continuous drip dispenser installed at the Zimmerman stock tank near Laredo, Tex.

of the dispersion material gave considerable trouble in maintaining a constant drip rate. The dispensing usually started out at a fairly high rate of drip, but it would gradually decrease and then stop, though some of the dispersion material still remained in the jug.

In this test the reduction in evaporation was slightly better than the previous tests. For a period of 29 days, during which time very little rainfall occurred, the saving amounted to 12 percent. For this period, the wind speed averaged 4.4 miles per hour, the average temperature of the surface of the water was $87^{\circ} \mathrm{F}$, and the evaporation was 6.5 inches. The amount of material applied was 2 pounds per acre per day.

The results of this test indicated that considerable improvement was needed in the dispersion material to increase its spreading ability. To obtain a good spreading rate, the drop of dispersion material must break up immediately upon impact with the surface of the water and must remain on the surface. The area covered by the film averaged about one-third of the surface area of the water and occasionally the film area would increase to about one-half. 


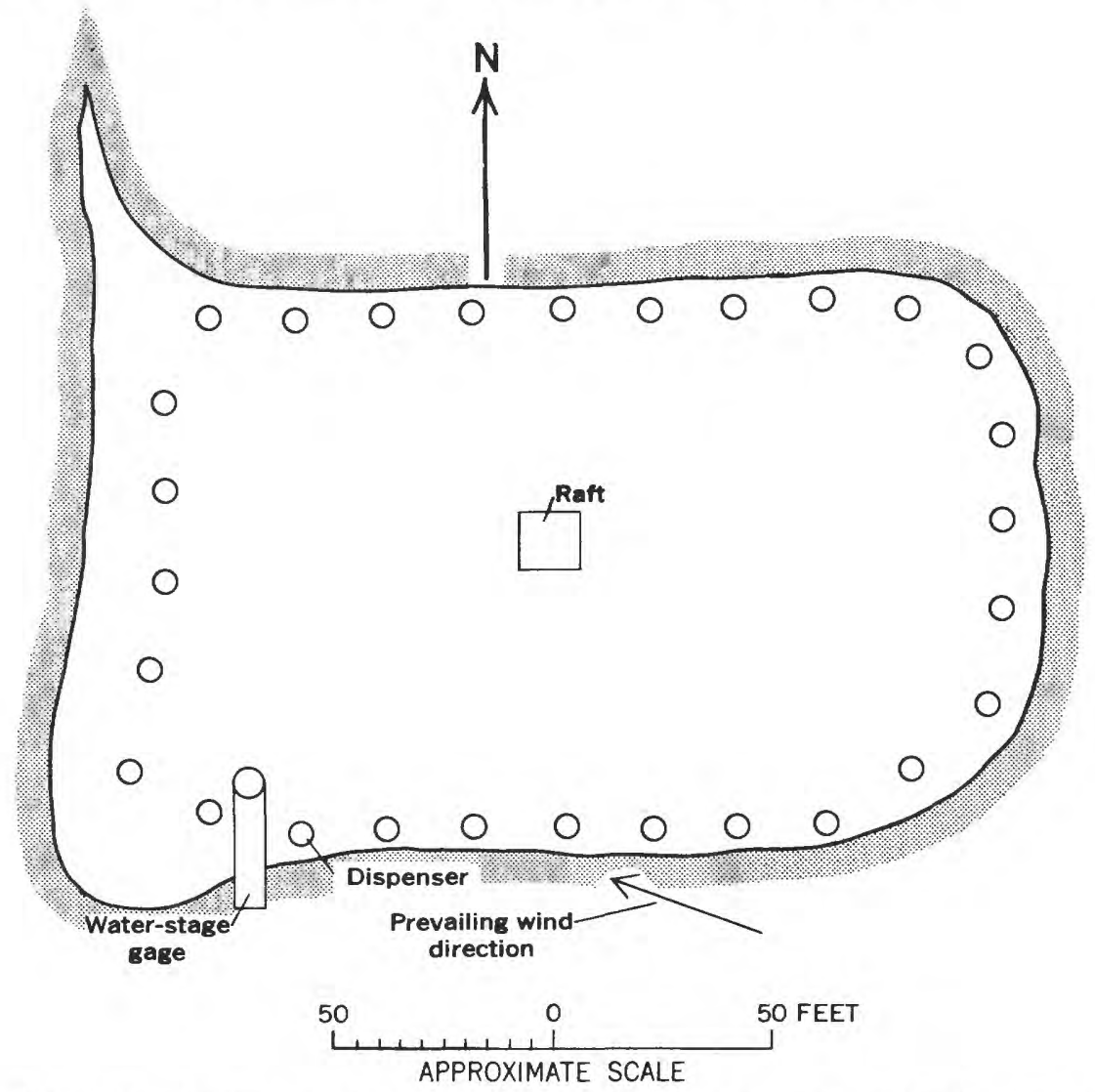

Figune 13.-Location of the drip dispensers around the perimeter of the Zimmerman stock tank.

During this test period there were no noticeable biological effects. The aquatic growths that were observed in the Briones tank did not appear in the Zimmerman tank.

The fourth field test was made on the Pinta Valle stock tank from October 1959 through April 1960. The use of the O/W type dispersion was continued, but hexadecanol was used instead of octadecanol.

The method of dispensing was changed from the continuous drip to a flow system which utilizes a needle valve to control the rate and time of flow. A sketch of this system is shown in figure 14. This sketch shows that the direction of the wind controls the flow of material from the container to the water surface and that the amount of flow is dependent on the opening of the needle valve. If no wind is present, the valve is closed by the spring. This is an improvement over the continuous drip system in that only the upwind dispensers allow the 

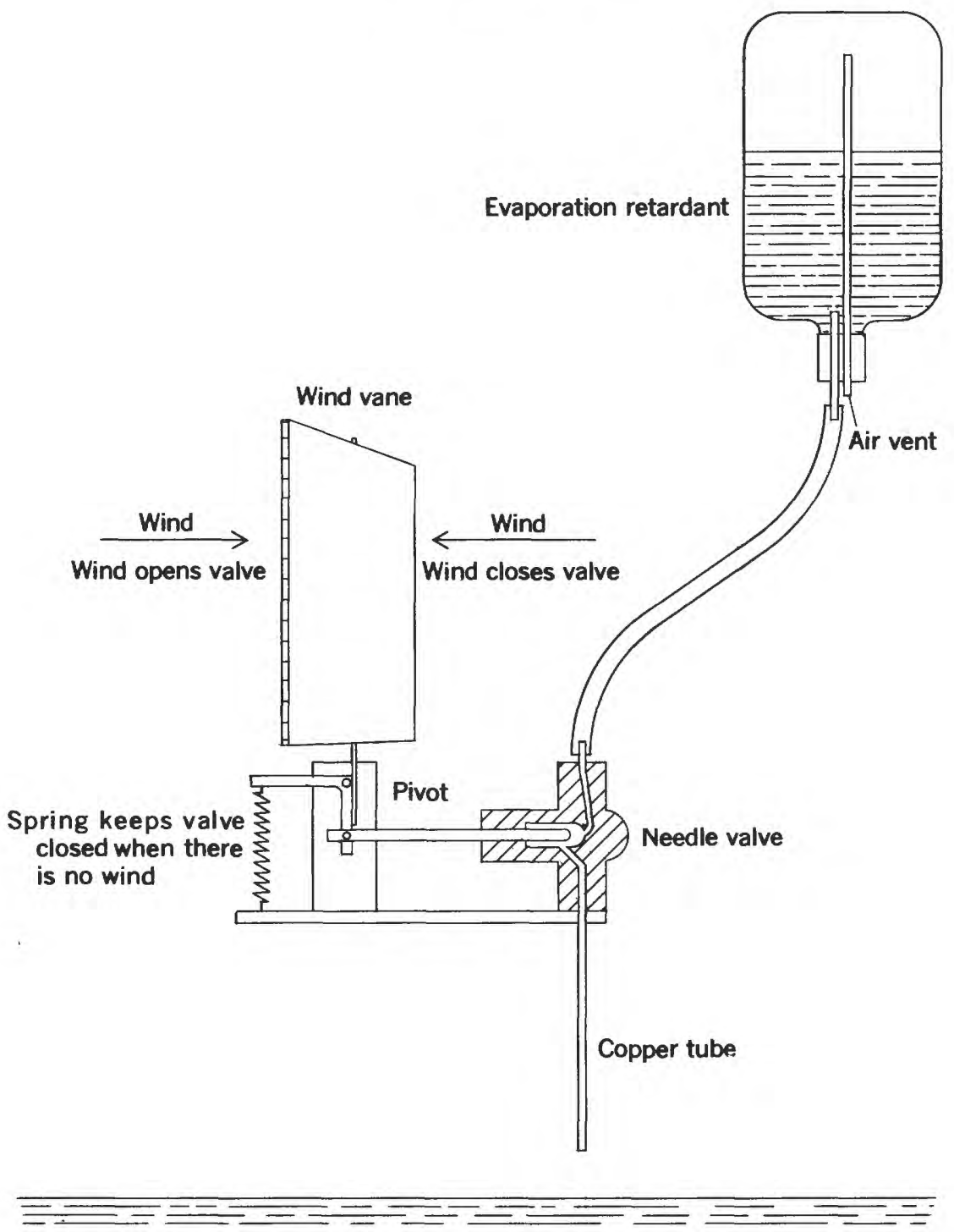

FIGURE 14.- Sketch of wind-controlled dispenser which shows how the fluid is controlled from the reservoir to the surface of the water.

dispersion material to flow onto the surface of the water and move downwind.

The location of the 16 dispensers around the perimeter of the tank is shown in figure 15. The dispensers were spaced about 35 feet apart and each dispenser was located about 6 feet from the shoreline. 


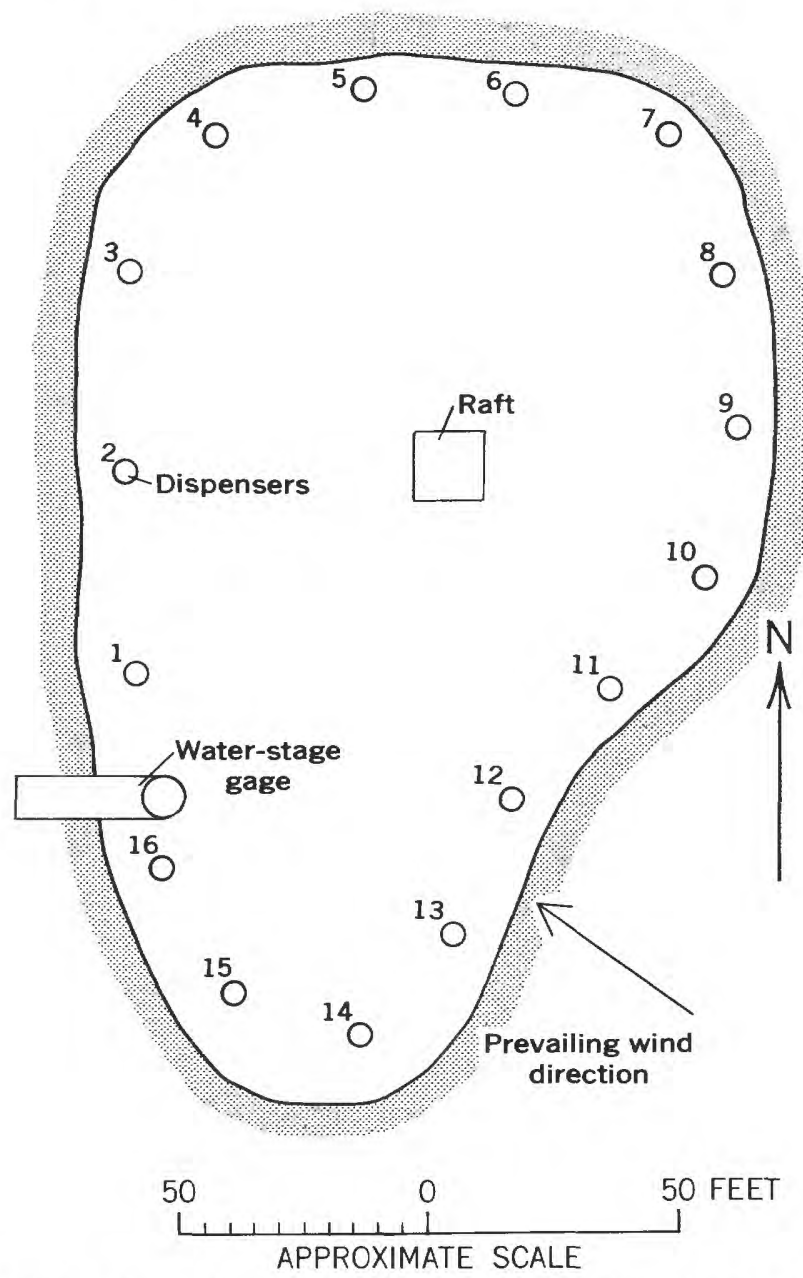

Figure 15.-A sketch of the Pinta Valle stock tank showing the location of wind-controlled dispensers.

During this test no significant saving in evaporation was observed, because the dispersion material could not flow through the dispenser. Either the material was too thick or the valves were continually clogged by small pieces of solid hexadecanol. The thickening of the dispersion is believed to have been caused by storing the material in the sunlight. Daily heating and cooling would cause some separation between water and hexadecanol and the separated hexadecanol would become very thick. Whenever the dispersion did flow through the dispenser, the film formation from the despersion was very slow and much of the material was deposited on the downwind shore without film formation. 
No biological effects were observed, probably because of the poor film coverage.

The fifth field test was conducted on Pinta Valle stock tank from June 11 to June 30, 1960. In this test, octadecanol was applied as a W/O type dispersion. The quantities of material used in each sample prepared for field use were 50 pounds of octadecanol, 500 pounds of distilled water, and 5 pounds of glyceryl monostearate (self-emulsifying). The method of mixing was the same as that of W/O type dispersions in the laboratory.

The method of dispensing was the same as that used in the previous test, but the container for the dispersion material was replaced by a 5 -gallon can.

In the previous test, 16 dispensers were utilized. In this test, however, only eight dispensers were necessary, because the spreading characteristics of the dispersion material had improved considerably with the change in formulation. Using the same numbering system as in the previous test, a dispenser was installed at each odd-numbered location. The even-numbered locations were not used.

The dispersion material broke up rapidly when placed on the surface of the water and formed a film much faster than the materials used in the previous tests. The amount of octadecanol applied was 6 pounds per day per acre. For wind speeds of less than 5 miles per hour, almost complete film coverage was obtained, and at speeds of more than 5 miles, bands of film extended from the dispenser to the downwind shore. These bands varied from 10 to 50 feet in width. The reason for the variation in width is believed to be a function of wind velocity and the amount of lateral spreading before movement downwind began. If the material is dispensed in areas sheltered from the wind, a considerable amount of lateral spreading has been observed which in turn increases the width of the band.

The results of this test indicated a saving in evaporation of 12 percent for the complete test period of 20 days. During this time, the average wind speed was 7.0 miles per hour, the average temperature of the surface of the water was $83^{\circ} \mathrm{F}$, and the evaporation was 4.3 inches.

In addition to the film test just described, a test was made of a floating barrier to retard the loss of film to the shoreline. The barrier was made of plastic tubing which had an outside diameter of five-eights inch. In order for the tubing to hold its shape and maintain buoyancy, it was inflated with air and placed around the tank about 6 feet from the shoreline. Part of the floating barrier is shown in figure 16 . 


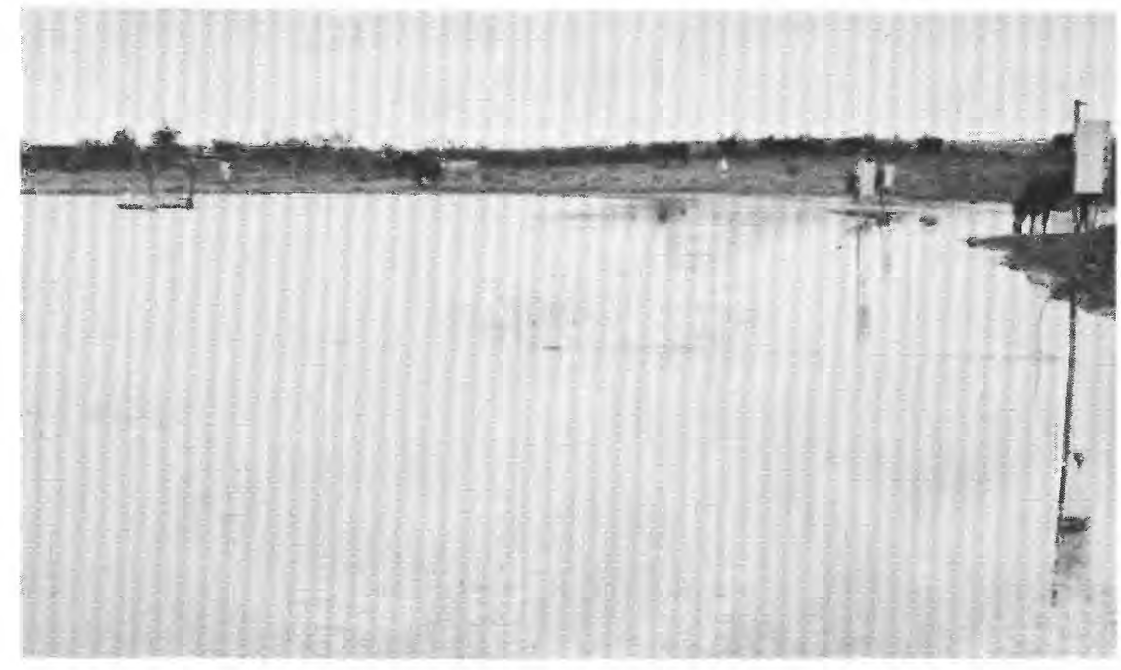

Figdre 16.-Floating barrier installed on the Pinta Valle stock tank.

The effect of the barrier in retarding the movement of the film was negligible, because the film would slip underneath the barrier with very little loss of velocity. Thus, the use of floating barriers would not appreciably increase the life of the film, which is considered to be the time of travel of the film between the upwind and downwind shores.

For the fifth test, the biological effects were certainly noticeable. At the start of the test, very little aquatic plants and algae were observed growing in the tank. At the end of 3 weeks of treatment, however, a considerable amount of algae and aquatic plants, such as chara, spirogyra, and najas, were observed in the tank. Some of this growth is shown at the surface of the water in figure 16, which was taken at the end of the test. As the dispensers were between the shore and aquatic vegetation on the surface, the movement of the film downwind through the vegetation on the surface was impeded considerably.

The sixth field test was made on the Carlos stock tank. A dispersion of octadecanol was applied in the same manner as the fifth test. The quantities of material used for each sample were changed as follows: 500 pounds of distilled water, 80 pounds of octadecanol, and 8 pounds of glyceryl monostearate (self-emulsifying). The method of mixing was the same as that used in the fifth test.

In this test, nine wind-controlled dispensers were installed about 50 feet apart and about 8 feet from the shoreline (fig. 17). The test began on July 10,1960, upon completion of the installation, and ended on July 31, 1960, when the supply of octadecanol was exhausted. The 
application rate was the same as that of the previous test -6 pounds of octadecanol per day per acre.

The results of this test for the 22 days shows a saving of 12 percent in evaporation. For the test period, the evaporation was 4.8 inches, the average wind speed was 5.9 miles per hour, and the average temperature of the water surface was $84^{\circ} \mathrm{F}$.

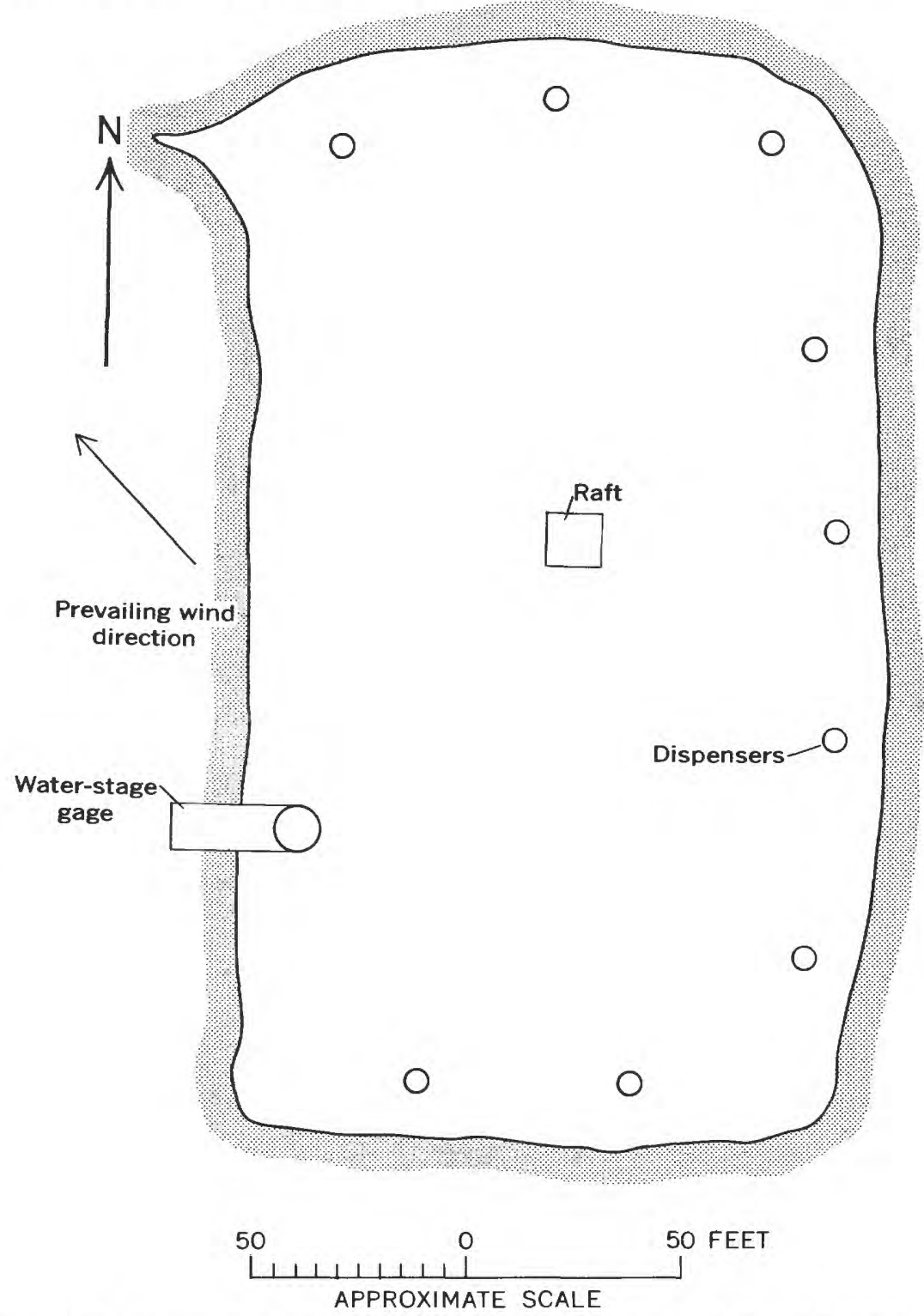

Frgure 17.- Sketch of Carlos stock tank showing the location of the wind-controlled dispensers. 
Film coverage was about the same as that of the other tests. The most significant observation of this test was that the water in the tank was very turbid at the start of the test and was almost clear at the end. This reduction in turbidity is believed to have been caused by the film. However, no reasonable explanation can be offered at this time. The only observed biological effect was that spirogyra was beginning to grow in the tank.

The seventh field test was made on the Carlos stock tank from August 16 to August 27, 1960. In this test a W/O type dispersion of hexadecanol was applied and the nine wind-controlled dispensers were continued in use at the same locations (fig. 17). The quantities of the material for each sample were as follows: 500 pounds of distilled water, 45 pounds of hexadecanol, and 4.5 pounds of glyceryl monostearate (self-emulsifying). The method of mixing was the same as that used in the laboratory for the $\mathrm{W} / \mathrm{O}$ type dispersions.

The rate of application was 5 pounds per day per acre and film coverage was about the same as that of the octadecanol test. However, it was noted that light winds collapsed the film over most of the surface area of the tank. The collapsed film would form small streaks of solid material which would tend to sink. Very little of the collapsed film was in evidence during the previous octadecanol test.

The results of this test were not as good as those of the octadecanol test and a reduction in evaporation of only 7 percent was obtained for a 12-day period. The poor results are believed to have been caused by the collapse of the hexodecanol film. During the test period, the average wind speed was 6.4 miles per hour, the average temperature of the surface of the water was $84^{\circ} \mathrm{F}$, and the evaporation for the period was 2.4 inches.

A considerable amount of spirogyra was growing in the tank at the end of the test. The rapid growth of vegetation is attributed to that effect of the film which decreases the turbidity of the water, thereby allowing greater penetration of sunlight for photosynthesis. The film also tends to increase the water temperature, thus creating a more favorable environment for vegetal growth.

The eighth field test was made on the Carlos stock tank from September 10 to September 23, 1960. Octadecanol was applied as a $\mathrm{W} / \mathrm{O}$ type dispersion and in the same quantities of material as the sixth test. The nine wind-controlled dispensers were continued in use at the same locations (fig. 17) and the rate of application of octadecanol was 5 pounds per day per acre.

Near the end of this test the dispersion thickened to the point where it no longer had any fluidity. The loss of fluidity prevented the dispersion from flowing through the valve. Previous to this time the dispersion did not change its characteristics appreciably. 
In field tests five through seven, the skies were generally partly cloudy and air temperature ranged from $80^{\circ} \mathrm{F}$ to $100^{\circ} \mathrm{F}$. Thus the temperature of the dispersion material did not change appreciably. At the end of this test period, however, the skies were generally clear and the air temperature ranged from $60^{\circ} \mathrm{F}$ to $95^{\circ} \mathrm{F}$. The material is believed to have thickened because the radiation from the sun was more intense when the sky was clear than when the sky was cloudy; thus, the material was heated to a higher temperature. As a result of the increased heating, some or all of the alkanol would be melted, after which it would solidify during the cool nights. The rate at which solidification occurs determines the fluidity characteristics of the material, as previously noted in the laboratory studies.

During the test, the average temperature of the water surface at Carlos tank was $84^{\circ} \mathbf{F}$, while that at Pinta Valle tank it was $80^{\circ} \mathrm{F}$-a difference of $4^{\circ} \mathrm{F}$. Also, it was observed at the end of the test that at 9 feet below the water surface a temperature difference of $4.5^{\circ} \mathrm{F}$ existed between the tanks. This observation was unusual because the temperature difference at the surface was to be expected while that below the surface was expected to remain at the $0.5^{\circ} \mathrm{F}$ difference observed at the beginning of the test. The difference in temperature at the surface of the tank is believed to have been caused by the film, as the tanks are only 2 miles apart and measured meteorological parameters indicate that the evaporation rate would have been nearly the same if no film had been applied to the Carlos tank. The difference in temperature below the surface was also attributed to the film.

The heating of water below the surface as a result of the film was never considered important until this test. To determine the magnitude of this heating in terms of energy, a computation was made to determine the amount of energy necessary to raise the temperature of the water $4^{\circ} \mathrm{F}$ in 14 days, assuming that the average depth of water in the tank is 9 feet. The computation for the test period ind inated $600 \mathrm{cal} \mathrm{cm}^{-2}$ would be necessary to raise the temperature of the water in the tank.

For the test period, it is of interest to determine the disposition of the energy which became available as a result of the reduction in evaporation. It has previously been computed that $600 \mathrm{cal} \mathrm{cm}^{-2}$ was used to increase the temperature of the water or increase the energy storage. It was also noted that the film had increased the temperature of the water surface by $4^{\circ} \mathrm{F}$. From the increase in temperature, the amount of energy lost by back radiation and conduction to the atmosphere is computed to be $700 \mathrm{cal} \mathrm{cm}^{-2}$. The sum of these two items is $1300 \mathrm{cal} \mathrm{cm}^{-2}$, which is the energy that would have been used for evaporation but was partly dissipated to the atmosphere and partly went into storage. 
During the test period, the amount of energy utilized by evaporation at Pinta Valle was $4150 \mathrm{cal} \mathrm{cm}^{-2}$. If it is assumed that this would have been the energy utilized by eraporation at Carlos, the reduction in eraporation can be determined from the above total. The percentage reduction is then computed to be 31 percent, of which almost half the reduction was being used to increase the amount of energy in storage. Another method of computing the actual evaporation reduction is by determining the evaporation difference between the Pinta Valle and Carlos stock tanks. The reduction in evaporation, based on this difference, was computed to be 27 percent, which is fairly close to the 31 percent reduction. The difference results from the uncertainty as to the exact amount of energy that went into storage. The method of determining the evaporation reduction based on the evaporation rates from the two tanks does not take into account the amount of energy going into storage. Upon completion of the test, much of the additional energy in storage is available for increasing the evaporation rate over that which would normally occur. The increased rate of evaporation will continue until the additional energy is reduced to zero. However, another important consideration should be given the 27 percent reduction figure. If the test had continued under the same meteorological conditions, then it would be logical to expect that energy going into storage as a result of the film would become negligible. At this point, the same percentage reduction in evaporation would continue, with the exception that the energy previously stored in the reservoir would now be dissipated to the atmosphere by condition and radiation.

The energy contributed to storage, as a result of the film, complicates the problem of evaluating the reduction in evaporation by the Harbeck and Koberg (1959) technique. If a film could be applied in such a manner so that it would continually cover the entire water surface for an indefinite time, a period could be selected, for the above mentioned evaluation technique, that would start and end at any time after the temperature of the water surface had completed its rise as a result of the film. However, present methods of applying and maintaining the film for most reservoirs have never been completely succossful in obtaining complete coverage and, even if complete film coverage is obtained, it can be maintained only for a short duration of time. Therefore, in using the Harbeck and Koberg (1959) evaluation technique to determine the reduction in evaporation, periods should be selected, if possible, when the energy stored in the reservoir as a result of the film is not significant.

To avoid errors due to the film's storing energy in the reservoir, it is possible to determine reduction in evaporation by eraluating the 
complete film test plus the time necessary to dissipate the energy stored in the reservoir by the film. The length of time for the energy to be dissipated after treatment is stopped should not require more than 2 weeks. Of course, when such a period is chosen, the potential reduction in evaporation, that is if the test had continued for an indefinite time under the same meteorological conditions, is not known, but it does give the actual reduction in evaporation.

In the earlier tests made near Laredo, the results obtained in evaporation reduction did not consider that the increase in energy storage, resulting from application of the film, was a significant item. Because the analyses did not take into account the utilization of stored energy in increasing evaporation as the film deteriorated, the computed reduction figures are probably in error; but they do serve a useful purpose in determining the relative effectiveness of each test.

The results of this test based on the difference in evaporation rates for the Carlos and Pinta Valle tanks indicated that a reduction in evaporation of 27 percent could be obtained if the conditions of the test prevailed indefinitely; but this does not appear practicable. For the test period of 14 days, the average wind speed was 4.1 miles per hour and the evaporation was 2.1 inches.

The biological growth observed in the previous test continued through this test. However, this growth did not reach the surface of the water.

The ninth field test was made on the Essar Ranch Lake from August 31 to September 22, 1960. In this test, octadecanol was applied as a $\mathrm{W} / \mathrm{O}$ type dispersion in the same proportions of material as in the sixth field test, and only seven wind-controlled dispensers were installed instead of nine. The dispensers were located about 100 feet apart and along one side of the lake as shown in figure 18 . The rate of application of octadecanol was approximately 1 pound per day per acre.

It should be noted that the dispensers were twice as far apart and each band of film formed downwind was twice as wide as those in the previous tests. This difference was created by the position of the earthfill dam on the upwind shoreline which sheltered the surface of the water along that shore from the wind. The sheltering effects allow more time for the film to move laterally from the dispenser before beginning its movement downwind. Once this downwind movement begins, very little lateral movement is obtained as illustrated in figure 19, which shows a band of film extending downwind with a fairly constant width. In this test the average wind speed was about 5 miles per hour. 


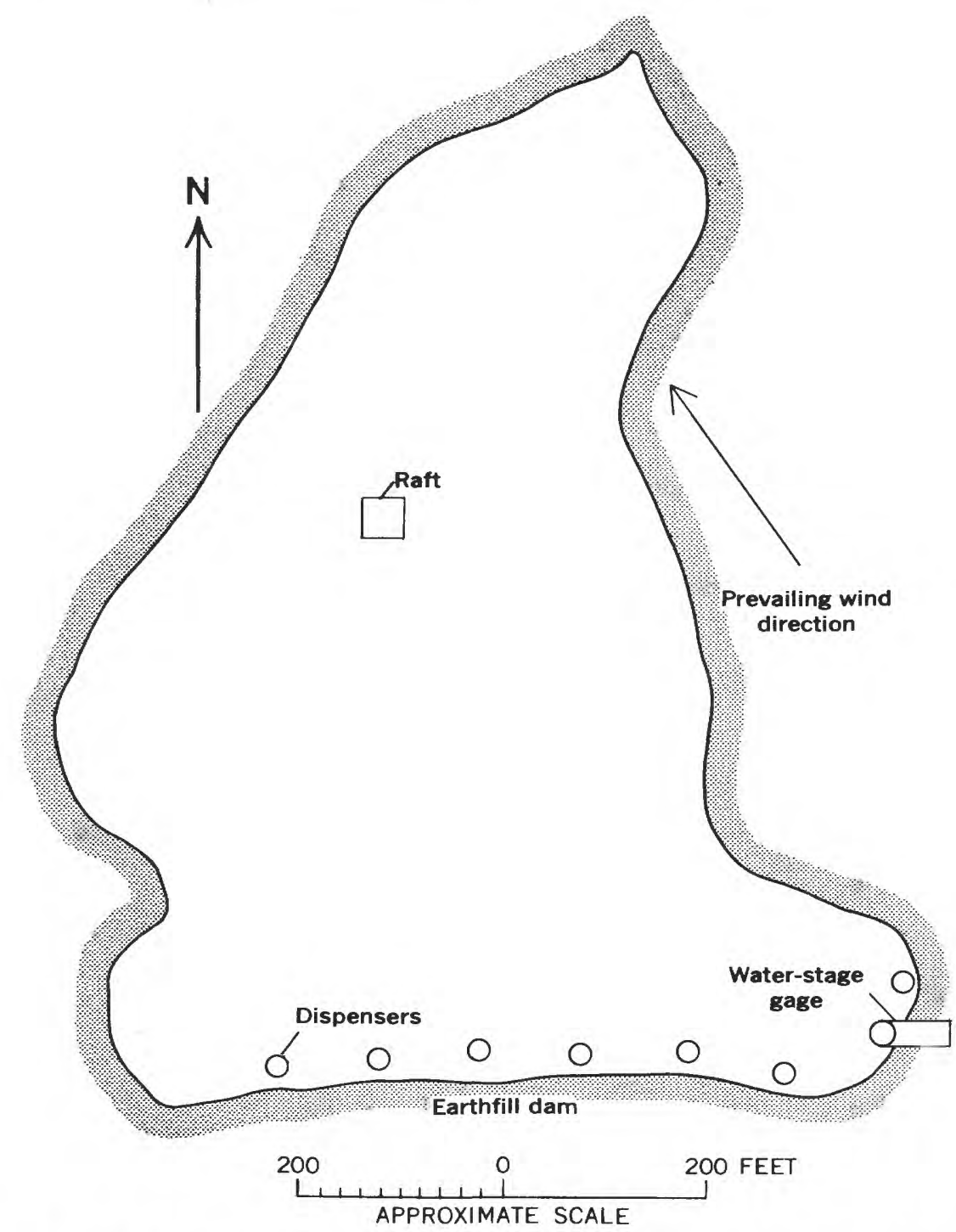

Figure 18.-A sketch of the Essar Ranch Lake near San Antonio, Tex., showing the location of the seven dispensers. 
The movement of the film was always from the upwind to the downwind shoreline. After reaching the shoreline, the film would form a white material, similar to that of the dispersion. If the white material was on the upwind shoreline, owing to a reversal of the wind, all the material would move downwind at the same time. Therefore, the film coverage from this material was of little value in reducing evaporation.

One observation noted for the first time at the Essar Ranch Lake test was the increase in temperature of the surface of the water as it moved downwind with the film. In order to obtain data on this observation a temperature recorder was installed 2 weeks before treatment at the water-stage gage (fig. 18). For this untreated period, the watersurface temperature at the raft averaged $0.6^{\circ} \mathrm{F}$ higher than at the water-stage gage. After treatment began on August 31 and until September 6,1960 , the average difference in temperature was $1.8^{\circ} \mathrm{F}$. The increase in temperature between the two points of measurement is considered to have been caused by the film. In both periods of

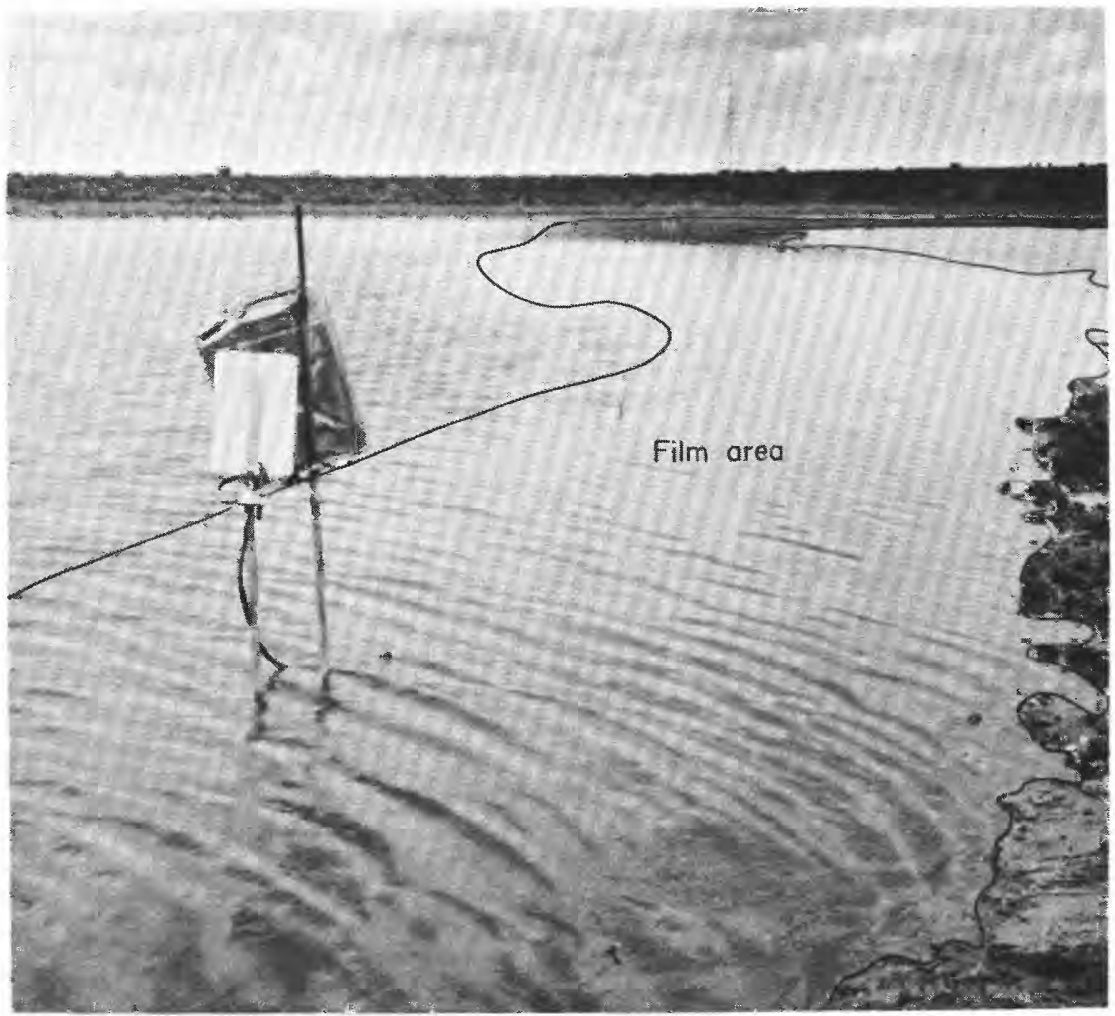

FIgURE 19. A band of film approximately 100 feet in width extending from the upwind shore to the downwind shore, a distance of about 700 feet. 
comparison, the wind velocity and air temperature were not greatly different.

One possible explanation of the increase in temperature at the water surface as it moves downwind is the effect of ripples. In the absence of a film, the water at the surface is moved by the wind in the downwind direction. As the water moves downwind it is heated by incoming radiation. However, ripples and small waves tend to mix the water at the surface with water below the surface, so that the difference in temperature at the surface between the upwind and downwind shores is not greatly different. In the presence of a film, the ripples become suppressed; this reduces the mixing of water at the surface with that below. Consequently the water at the surface increases in temperature as it moves downwind. During the day at the Essar Ranch Lake, differences in temperature of $6^{\circ} \mathrm{F}$ have been observed between the upwind and downwind shores. It should be pointed out that the film may be multilayer downwind and a broken monolayer upwind, resulting in a greater temperature rise.

Another possible explanation of the increase in temperature downwind is that the wind induces circulation in the pond. The surface water moves downwind, causing cooler bottom water to be brought to the surface at the upwind shore.

For the ninth field test, results are given for the 6-day period of August 31 to September 6, 1960, because this was the longest period in which rainfall did not occur. Also, the direction of wind remained favorable for operating the dispensers. For this period the computed reduction in evaporation, that is, the reduction obtained if the test conditions exist for an indefinite time, was 25 percent. The average wind speed was 4.5 miles per hour, the average temperature of the surface of the water was $87^{\circ} \mathrm{F}$, and the evaporation was 0.9 inches.

In the ninth field test, the application rate of octadecanol per acre was much lower than that of the eighth test, and yet the reduction in the evaporation was almost the same. The reason for this was that the average distance of travel for the film at Essar Ranch Lake was about 600 feet as compared with 100 feet for the Carlos stock tank, and in this case the ratio of distance is about the same as the ratio of the application rates.

No significant observations were made regarding biological changes. The aquatic growths that were observed in the stock tanks were also observed in the lake; however, these growths were believed to be present before film application started. Also, during this test, about 100 head of prize cattle used this lake for drinking purposes but they were not adversely affected by the film. 


\section{CONCLUSIONS ON FIELD TESTS}

The results of the field tests indicate that some success was obtained in applying a monolayer to the surface of the water to reduce evaporation. The main consideration in the effectiveness of the monolayer was the percent reduction in evaporation. Generally, the percent reduction in evaporation refers to that which can be expected if the test conditions remain the same for an indefinite time. The economics of such an application have not been considered, mainly because they are dependent on the application rate, which in turn is depencent on the distance the film travels downwind. The most successful test was the eighth, where a reduction of 27 percent was obtained. There is no apparent reason why this test should be more successful than tests five and six, where the method and form of application were the same. Of course, tests five and six were not corrected for energy storage, but available data do not indicate any appreciable change in the energy storage as a result of the film.

The difference in degree of success may be attributed partly to wind speed. The arerage wind speed was 4.1 miles per hour for the eighth test as compared with 7.0 and 5.9 miles per hour for tests fire and six, respectively. This would indicate that the effectiveness of tle film may be dependent on the speed of the wind. The relative humidity of the air and the temperature of the water surface may also affect the efficiency of the film. However, for these tests there was no appreciable difference either in the temperature of the water surface or in the relative humidity of the air.

The alkanols that were used to form films for these field tests were dodecanol, hexadecanol, and octadecanol. Of the three, octadecanol was the most successful in reducing evaporation. This supports the general belief that the longer the alkanol chain, the more efficient it is in retarding evaporation. The only significant difference in the alkanols observed in the field was that the film from hexadecanol collapsed at a lower wind speed than the film from octadecanol. The water temperature was $81^{\circ} \mathrm{F}$ during this test. It is believed that as th temperature of the water approaches the melting point of the alkar ol, the surface pressure at which the film will collapse decreases. However, there is very little laboratory data to support this theory.

Before any film can be successful, it must be applied as rapidly as it is lost from the surface of the water. Of the various methods of applying the film tested in the field, the wind-controlled gravity-type dispenser was considered better than any other method. Some of the desirable features of this dispenser are that the force of gravity moves the material from the container to the surface of the water, the direction of the wind determines when the material is to be applied to the 
surface, and the simplicity and low cost of construction makes it practical for field use. Improvements probably can be made in this dispenser to obtain more efficient film coverage; one such improvement would be to make the rate of application dependent on wind speed as well as wind direction. No specific rule can be recommended at this time concerning the interval at which dispensers should be located. Tests eight and nine have indicated that the exposure of the water surface to the wind at the point of application determines the distance of lateral spreading. Until more information is available on the spacing, only a trial method can be recommended to determine the distance of lateral spreading with respect to wind speed.

Alkanols have been applied in the field tests, as a liquid dissolved in ethanol, as an $\mathrm{O} / \mathrm{W}$ type dispersion, and as a $\mathrm{W} / \mathrm{O}$ type dispersion. Of the three forms tested, the $\mathrm{W} / \mathrm{O}$ type dispersion is considered to be the most promising because of its rapid spreading rate. If safety and economics are also considered, it will most likely compare equally well with any other form of application. However, there is still a need for improving the dispersion material, especially in regard to viscosity and separation. The field tests have indicated this to be the most serious problem.

The field tests did not indicate the distance downwind a film will travel and still remain effective in reducing evaporation. Test nine indicated the film to be still effective after traveling 600 feet. However, its effectiveness any distance beyond this point is uncertain. More studies are certainly needed to define the effectiveness of the film as it moves downwind because most reservoirs have a downwind distance that far exceeds 600 feet.

In connection with the studies on the movement of film downwind, the increase in temperatures of the surface of the water should also be studied. Test nine indicated that the increase in temperature can be significant. Possibly this test might be used as a method to determine the effectiveness of the film as it moves downwind.

The field tests have indicated that certain biological changes can be expected as a result of the film. The most noteworthy of these changes is the increase in growth of aquatic plants around the perimeter of the stock tank. The increase in growth is attributed to the rise in temperature of the water and to the decrease in turbidity which allows greater penetration of sunlight. No harmful effects on wildlife and cattle were observed. This does not necessarily mean that no harmful effects will ever arise from the presence of a film, but it does seem to indicate that very little, if any, harmful effect can be expected. 
In the previous study by Cruse and Harbeck (1960), it was bolieved that some destruction of the film was being caused by bacteria. In the present studies, the travel time of the film across the stock tanks and the small lake was only a matter of minutes, so the effect of the bacteria on the film was negligible.

The feasibility of applying monolayers to small stock tanks to reduce evaporation is very questionable at this time. The stock tanks used in the field were less than 1 acre in surface area with one exception. The amount of retardant material needed per acre to obtain a reduction in evaporation over a small area is much greater than that needed for a larger reservoir because of the shorter travel distance of the former. For the small stock tanks, there may be a more efficient and economical method of reducing evaporation. One such method is to place a floating cover over part of the surface of the water. The surface of the water would thus be open around the perimeter of the tank so that cattle would have access to the water. The cover could be constructed so that most of the solar radiation would be reflected. With less penetration of heat, the water in the tank presumably could be kept at a lower temperature. There are possibly other mothods, but this one seems to be the most practical at this time. There may be some objection to a cover because it limits the use of water by wildlife, but when the total value of the water is considered, all the detrimental effects will be outweighed.

\section{SUGGESTIONS FOR FUTURE WORK}

The results of the laboratory and field work have indicated that more studies are needed to define or improve certain aspects in the use of monomolecular films in suppressing evaporation.

\section{LABORATORY STUDIES}

The effect of impurities.-In the previous investigation (Cruse and Harbeck, 1960), it was suggested that impurities in the retardant materials may decrease the film's capacity to reduce evaporation. This problem has not been resolved, and a fundamental laboratory st'idy on this aspect is still needed.

In addition, it has been noted in the course of this investigation that hexadecanol gives dispersions having somewhat different viscosity properties from the octadecanol or eicosanol. Some preliminary work by Arista Industries (written communication, 1960) utilizing gasphase chromotography indicates the presence of undetermined impurities in various hexadecanol compositions sold by this company. Even in previous work (Cruse and Harbeck, 1960) hexadecanol 
seems to behave somewhat differently from the octadec'nol, when used as a solid.

These phenomenon suggest that hexadecanol contains impurities which are originally formed as a result of the hydrogenation of vegetable oil or animal fat, and which distill, codistill, or azeotropically distill in the same range $\left(316^{\circ}\right.$ to $336^{\circ} \mathrm{C}$ ) as does the hoxadecanol. The determination and characterization of these impurities could best be done by tapor phase chromotography, also, comparative determinations could be made for octadecanol and the higher homologs.

Polymorphism of long chain alkanols.-Vines and Meakins (1959) have described phase transformation in commercial hexadecanols used for water conservation. The studies indicated that phase transformation occur's at about $30^{\circ}$ to $40^{\circ} \mathrm{C}$ and that it affects the ability of the material to spread. In the course of this investigation, it has been noted that when a W/O type dispersion is cooled rapidly, it has better spreading properties than a similar dispersion which is not cooled rapidly. Further, if the material had been allowed to stand at temperatures about $90^{\circ} \mathrm{F}$, thickening of the dispersion would have. occurred with attendant difficulties in the application procedure. These observations indicate that both hexadecanol and perhaps the homologous series from $\mathrm{C}_{13}$ or $\mathrm{C}_{14}$ to $\mathrm{C}_{22}$ possess polymorphic properties. Fundamental laboratory studies of the problems of the rate of cooling and the effect of storage are needed for a better understanding of this phenomenon.

The effect of relative humidity.-In the theoretical discussions it was pointed out that the film retards the movement of water molecules from the water as well as from the atmosphere above the film to the water. Laboratory studies are needed to define this aspect with regard to the relative humidity of the air and the surface pressure of the film.

\section{FIELD STUDIES}

The effect of the wind.--In the course of this investigxtion it has been demonstrated that the rate and direction of movement of the film are dependent on the wind. Studies are needed to define the distance downwind the film remains effective and also whether the fim remains effective regardless of the rate of movement. In addition, the lateral movement of the film should be defined with respect to wind speed.

Use of docosanol and eicosanol.-Laboratory studies have indicated that docosanol and eicosanol have the same spreading characteristics, when they are in the W/O type dispersion form, as hexadecanol and octadecanol. Field studies are needed to determine whether higher reduction in evaporation can be obtained with the longer chain alkanols. 
Increase in temperature of the surface of water.-Further studies are needed to determine whether the rate of increase in the temperature of water at the surface is an index of the effectiveness of the film in reducing evaporation.

Other possible methods to reduce evaporation.-In investigation is considered warranted in the use of reflective solar cover as a method of reducing evaporation from small stock tanks. Preliminary studies indicate that the percent of water-surface area coverage is an indication of the reduction in eraporation.

Other possible uses of alkanols.-In Japan, dispersions of alkanols are being used to increase the temperature of water in the rice paddies to mature the crop at an earlier date. This dispersion material has also been applied to irrigation water. By this application, \& monomolecular film is left on the soil which presumably reduces the evaporation loss from the soil. 


\section{REFERENCES CITED}

Becher, P., 1955, Principles of emulsion technology: New York, Fisinhold Publishing Corp., 149 p.

1957, Emulsions: Theory and practice: New York, Reinhold Publishing Corp., 382 p.

Cruse, R. R., and Harbeck, G. E., 1960, Evaporation control research 1955-58: U.S. Geol. Survey Water-Supply Paper 1480,45 p., 1 pl., 14 figs.

DeJong, H. G. B., 1949, Crystallization-coacervation-flocculation, chap. 8 in Kruyt, H. R., ed., Reversible systems, v. 2 of Colloid science: New York. Reinhold Publishing Co., Inc., p. 243-248.

Griffin, W. C., 1949, Calculations of "HLB" values of nonionic surfactants : Cosmetic Chemists Soc., v. 1, p. 311.

1954, Calculations of "HLB" values of nonionic surfactants: Cosmetic Chemists Soc. Jour., p. 249-256.

Harbeck, G. E., 1958, Mass-transfer studies in. Water-loss investigations: Lake Mead studies : U.S. Geol. Survey Prof. Paper 298, p. 29-35.

Harbeck, G. E., and Koberg, G. E., 1959, A method of evaluating the effect of a monomolecular film in suppressing reservoir evaporation: Jour. Geophysical Research, v. 64, no. 1, p. 89-93.

Harkins, W. D., 1952, The physical chemistry of surface films : New York, Reinhold Publishing Corp., 413 p.

Langbein, W. B., Hains, C. H., and Culler, R. C., 1951, Hydrology of stockwater reservoirs in Arizona: U.S. Geol. Survey Circ. 110, 18 p., 12 figs.

McArthur, I. K. H., and Durham, K., 1957, The influence of dosage on the efficiency of fllms of fatty alcohols for water conservation: Research, v. 10, p. 291-292.

Mansfield, W. W., 1955, Summary of field trials on the use of cetyl alcohol to restrict evaporation from open storage during the season 1954-55: Commonwealth Scientific and Industrial Research Organization, Div. of Indus. Chemistry, serial 74, 8 p., Melbourne, Australia.

Marciano, J. J., and Harbeck, G. E., 1954, Mass-transfer studies in Water-loss investigations: Lake Hefner studies, technical report: U.S. Geol. Survey Prof. Paper 269, p. 46-70.

Rideal, E. K., 1925, The influence of thin surface films on the evaporation of water : Jour. Phys. Chemistry, v. 29, p. 1585-1588.

Rosano, H. L., and La Mer, V. K., 1956, The rate of evaporation of water through monolayers of esters, acids and alcohols: Jour. Phys. Chemistry, v. 60, p. 348-353.

Vines, R. G., and Meakins, R. J., 1959, Phase transformation in commercial cetyl alcohols for water conservation: Australian Jour. Applied Science, v. 10, no. 2 , p. 190-200. 
TABLES 

TABLE 1.-Emulsifiers available for evaluation with water evaporation retarlants

\begin{tabular}{|c|c|c|}
\hline Type structure or formula & Trade name & $\begin{array}{l}\text { Hydrophil 3-Lipo- } \\
\text { phile Ba'ance }\end{array}$ \\
\hline Aralkyl sulfonate (90 percent active) & Ultrawet $\mathbf{K X}$. & 11.7 \\
\hline Aralkyl sulfonate (31.5 percent active) & Ultrawet $35 \mathbf{K X}$ & \\
\hline te. & Arlacel (Span) 20 & 8.6 \\
\hline itan monostear & Arlacel (Span) 60 & 4. 7 \\
\hline eryl monostear & Arlacel 165 & 5.5 \\
\hline leate.... & Atpet 200 & \\
\hline thylene ster & $\mathrm{G}-2151 \ldots \ldots$ & 16. 0 \\
\hline$-1-1-1$ & MYRJ 45 & 11. 1 \\
\hline mitate & Tween 40 & 15.6 \\
\hline yoxyethylene sorbitan & Tween 60 & 14.9 \\
\hline Polypropylene glycol m & & \\
\hline cent lauryl sulfate. & Deyhydag Wax & \\
\hline $\begin{array}{l}\text { Nonyl phenoxy polyoxyethylene ethanol condensation } \\
\text { product. }\end{array}$ & Igepal CO-210 & 12.8 (estinated) \\
\hline enol-polyoxyethylene condensation product.-. & Igepal $\mathrm{CO}$ & 13. I (estimated) \\
\hline ne... & Alkaterge C.. & 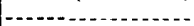 \\
\hline & Alkaterge $\mathrm{T}$ & \\
\hline int- & acid) & $-\cdots$ \\
\hline densation & ol NP-14. & \\
\hline - n & yl NL-30 & \\
\hline Oleyl s & Sarkosyl 0 & \\
\hline $\begin{array}{l}\text { Aralkyl sulfonate-polyoxyethylene condensation prod- } \\
\text { uct. }\end{array}$ & Nacconal NRSF & \\
\hline $\begin{array}{l}\text { Alkyl imidazole-N-carboxymethyl-N-hydroxy-N-hy- } \\
\text { droxyethyl sodium salt. }\end{array}$ & Miranol & \\
\hline $\begin{array}{l}\text { Alkyl imidazole-N-carboxymethyl-N-hydroxy-N-hy- } \\
\text { droxyethyl sodium salt. }\end{array}$ & Miranol & \\
\hline Cetyl bet & $\operatorname{Pr}$ & \\
\hline $\begin{array}{l}\text { Aralkyl su } \\
\text { Fatty alky }\end{array}$ & Agr & \\
\hline Fatty alky & nic FA-40_- & \\
\hline fied) & nic FA-75... & \\
\hline $\begin{array}{l}\text { Alkyl phenol-polyoxyethylene condensation product } \\
\text { (5 mols). }\end{array}$ & Hyonic PE-50 & \\
\hline $\begin{array}{l}\text { Alkyl phenol-polyoxyethylene condensation product } \\
\text { ( } 7 \text { mols). }\end{array}$ & Hyonic PE-70. & \\
\hline $\begin{array}{l}\text { Alkyl phenol-polyoxyethylene condensation product } \\
(9 \text { mols }) \text {. }\end{array}$ & Hyonic PE-90. & \\
\hline $\begin{array}{l}\text { Alkyl phenol-polyoxyethylene condensation product } \\
\text { (10 mols). }\end{array}$ & Hyonic PE & \\
\hline $\begin{array}{l}\text { Alkyl phenol-polyoxyethylene condensation product } \\
\text { (15 mols). }\end{array}$ & Hyonic PE-150 & \\
\hline $\begin{array}{l}\text { Alkyl phenol-polyoxyethylene condensation product } \\
\text { (30 mols). }\end{array}$ & Hyonic PE-300 & \\
\hline lfonic acid & & \\
\hline ethylene condensation pro & $\ldots$ & \\
\hline (modified) & is ES & $\ldots$ \\
\hline (ammonium) & $-\ldots$ & \\
\hline (sodium) & -- & 40 \\
\hline lide.n.t. & $\ldots-n-n$ & h-n-n \\
\hline ylene con & & \\
\hline- & 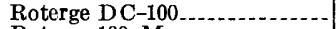 & 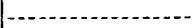 \\
\hline Alkanolamide & $100-M_{2} \ldots$ & 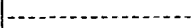 \\
\hline $\begin{array}{l}\text { Lauryl sulfate+aralkyl sulfonate +amine condensates } \\
\text { +EDTA. }\end{array}$ & & \\
\hline ed alkanolamide & & 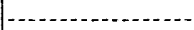 \\
\hline $\begin{array}{l}\text { Alkyl phenol-polyoxyethylene-ammonium sulfate con- } \\
\text { densation product. }\end{array}$ & Surco 57 & \\
\hline known. & & \\
\hline & $\mathrm{Su}$ & \\
\hline - surala (Iva sail).... & $30 \mathrm{~T}$ & \\
\hline 1 ether sulfate $\left(\mathrm{NH}_{4}\right.$ salt) & Trepen & \\
\hline $\begin{array}{l}\text { Tridecanol polyglycol ether sulfate (Triethanolamine } \\
\text { salt). }\end{array}$ & & \\
\hline yl diethanolamid & Trepolir & \\
\hline $\begin{array}{l}\text { Alkyl phenol-polyoxyethylene-iodine complex conden- } \\
\text { sate. }\end{array}$ & & \\
\hline Alk & & \\
\hline Clisave- & & \\
\hline - $-\ldots$ & & \\
\hline $\mathrm{T}$ & TLS 500 & \\
\hline & & \\
\hline ioctyl & O OT (100 percent) & \\
\hline
\end{tabular}


TABLE 1.-Emulsifiers available for evaluation with water evaporation retardants-Continued

\begin{tabular}{|c|c|c|}
\hline Type structure or formula & Trade name & $\begin{array}{l}\text { Hydrophile-Lipo- } \\
\text { phile Balance }\end{array}$ \\
\hline Fatty acid derivative of polypeptide ( $\mathrm{K}$ salt) & Maypon 4C & \\
\hline Fatty acid derivative of polypeptide (Na salt) & Maypon SK & \\
\hline Polyoxyethylene stearate & G-2151 (MYRJ-51) $\ldots \ldots$ & 16. 0 \\
\hline Aralkyl sulfonate. & $\mathrm{G}-3300$ & 11. 7 \\
\hline Sorbitan monooleate & Arlacel (Span) 80 & 4. 3 \\
\hline Polyoxyethylene sorbitan monooleate & Tween $80 \ldots$ & 15.0 \\
\hline Glyceryl lacto-oleate & Arista No. 6014 & --- \\
\hline Sodium lauryl sulfate........ & SLS-11 $\ldots \ldots$ & -- \\
\hline Triethanolamine lauryl sulfate & TEA-LS & $-\ldots$ \\
\hline Monoethanolamine lauryl sulfate & MEA-LS & 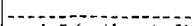 \\
\hline $\begin{array}{l}\text { Mono- and diglycerides of fatty acids+preservative } \\
\text { and antioxidant. }\end{array}$ & Atmos 300 & 4-5 (estimated) \\
\hline Polyoxyethylene sorbitan beeswax derivatives.... & $\mathrm{G}-1726$ & 5 \\
\hline Sorbitan sesquioleate & Arlacel 83 & 3.7 \\
\hline N-cetyl-N-ethyl morpholinium ethosulfate & $\mathrm{G}-263$ & 30 \\
\hline N-soya-N-ethyl morpholinium ethosulfate. & $\mathrm{G}-271$ & $25-30$ \\
\hline Polyoxyethylated fatty acid....... & Emulphor UN-430 & 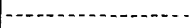 \\
\hline Polyoxyethylated regetable oil & Emulphor EL-260 . . & 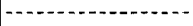 \\
\hline Polyoxyethylated regetable oil & Emulphor EL-719 $\ldots \ldots$ & 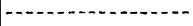 \\
\hline $\begin{array}{l}\text { Polyoxyethylated fatty alkanol. } \\
\text { N-COCO-amino butyric acid }\end{array}$ & Emulphor ON-870 & \\
\hline 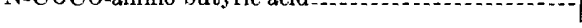 & 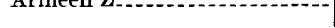 & \\
\hline
\end{tabular}

TABLE 2.-Water-in-oil emulsions using 250 grams of dodecanol as the oil

\begin{tabular}{|c|c|c|c|}
\hline Test & Emulsifying agent & $\begin{array}{l}\text { Amount of } \\
\text { emulsify- } \\
\text { ing agent } \\
\text { (grams) }\end{array}$ & Renuarks \\
\hline 1 1.. & Glycerol monostearate. & 25 & Smooth creamy liquid. Set to a paste \\
\hline 4 & $\begin{array}{l}\text { Sorbitan oleate } \\
\text { Sorbitan monostearate } \\
\text { Cetyl betaine }\end{array}$ & $\begin{array}{l}25 \\
25 \\
25\end{array}$ & $\begin{array}{l}90 \text { percent separated after } 24 \mathrm{hr} \text {. } \\
50 \text { percent separated after } 24 \mathrm{hr} \text {. } \\
\text { Emulsion gelled. Still a gel, but } 80 \text { per- }\end{array}$ \\
\hline $5 \ldots \ldots$ & Aralkyl sulfonate, 90 percent active $\ldots$.. & 25 & Some separation of oil but emulsion still \\
\hline $6 \ldots \ldots$ & Polypropylene glycol monostearate & 25 & Complete separation after $24 \mathrm{hr}$. \\
\hline
\end{tabular}

TABLE 3.-Oil-in-water dispersions of alkanols

\begin{tabular}{|c|c|c|c|c|c|c|}
\hline \multirow{2}{*}{ Test } & \multicolumn{2}{|c|}{ Oil phase } & \multicolumn{2}{|l|}{ Dispersing agent } & \multirow{2}{*}{$\begin{array}{l}\text { Water } \\
\text { (milli- } \\
\text { liters) }\end{array}$} & \multirow{2}{*}{ Remarks } \\
\hline & Alkanol & $\underset{\text { (grams) }}{\text { Amount }}$ & Type & $\underset{\text { (grams) }}{\text { Amount }}$ & & \\
\hline 7. & Octadecanol & 25 & Glyceryl monostearate, & 2.5 & 1,000 & Ser arated, 1-in. oil layer. \\
\hline - & ......do_. & 25 & - . - do & 5.0 & 1,000 & Serarated, 11/4-in. oil \\
\hline $9 \ldots$ & .....do_. & 25 & ...... do & 7.5 & 1,000 & $\begin{array}{l}\text { Serarated, 11/6-in. oil } \\
\text { lryer, 13/4-in. foam }\end{array}$ \\
\hline $10 \ldots \ldots$ & $\ldots$ do $\ldots . . . .$. & 25 & - do & 10.0 & 1,000 & $\begin{array}{l}\text { Serarated, } 11 / 4 \text {-in. oil } \\
\text { liyer, } 1 \frac{1}{2} \text {-in. foam }\end{array}$ \\
\hline & ..... do........ & 25 & Aralkyl sulfonate (Ultra- & 2.5 & 1,000 & Serarated, 78-in. oil layer \\
\hline & ..... do... & 25 & - do do & 5.0 & 1,000 & $\begin{array}{l}\text { Serarated, 11/8-in. oil } \\
\text { layer. }\end{array}$ \\
\hline 13 & $\ldots$........... & 25 & ......do.... & 7.5 & 1,000 & Serarated, 21/4-in. oil \\
\hline $14 \ldots . .$. & ......do... & 25 & ......do_. & 10.0 & 1,000 & $\begin{array}{l}\text { Separated, } 11 / 4 \text {-in. oil } \\
\text { layer, } 1 / 2 \text {-in. foam layer. }\end{array}$ \\
\hline
\end{tabular}


TABLES

TABLE 3.--Oil-in-uater dispersions of alkanols-Continued

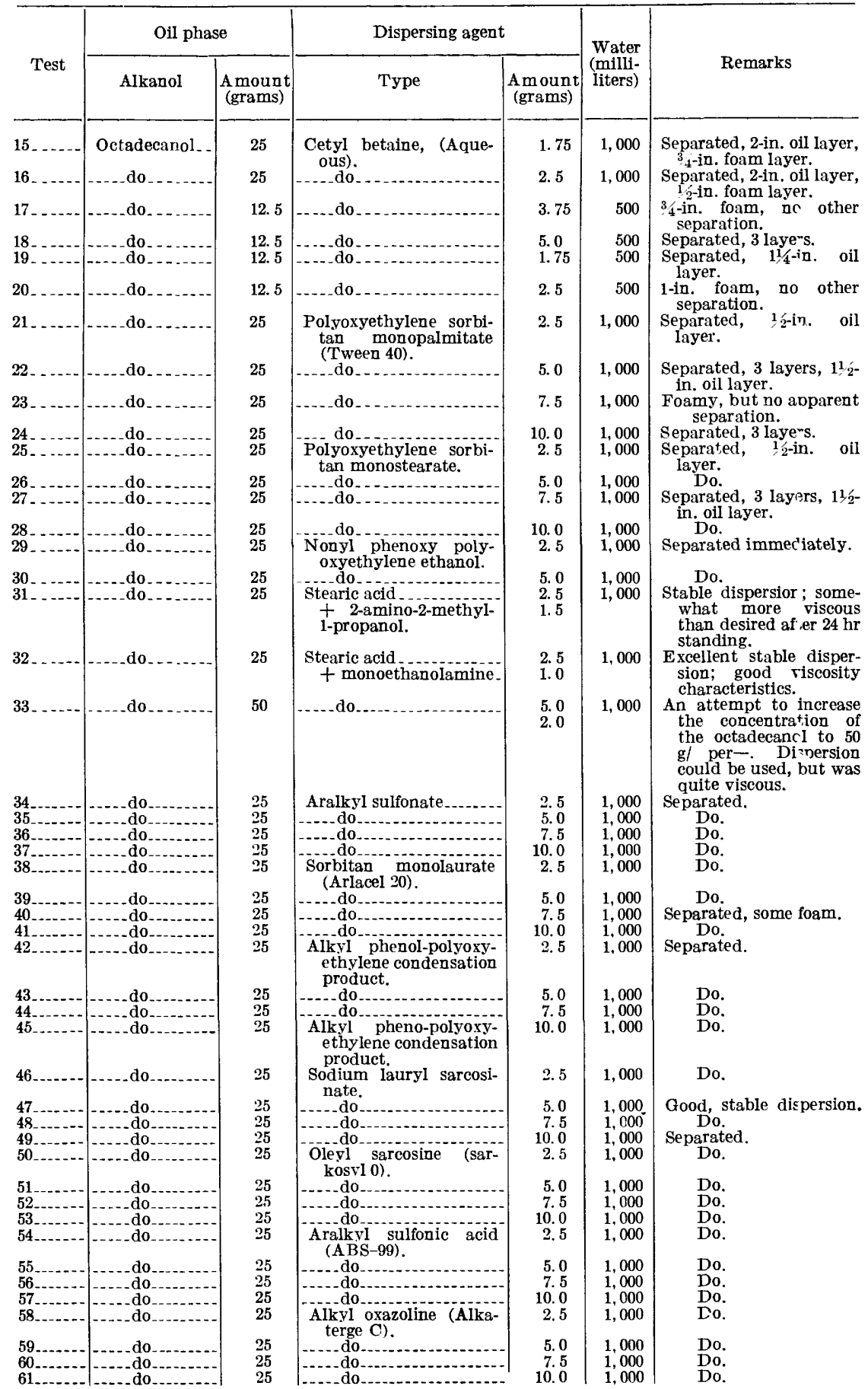


TABLE 3.-Oil-in-teater dispersions of alkanols-Continued

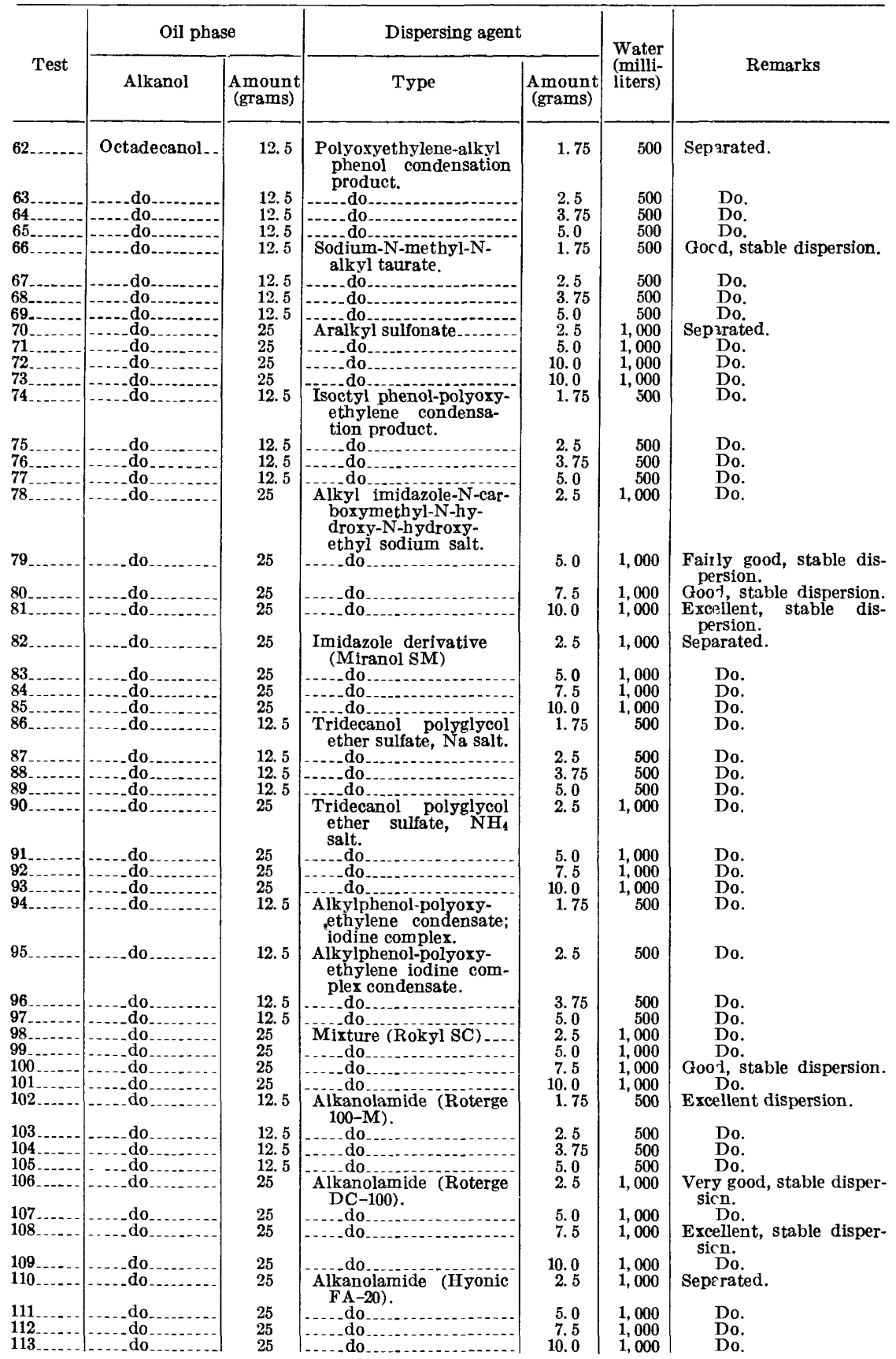


TABLES

TABLE 3.-Oil-in-water dispersions of alkanols-Continued

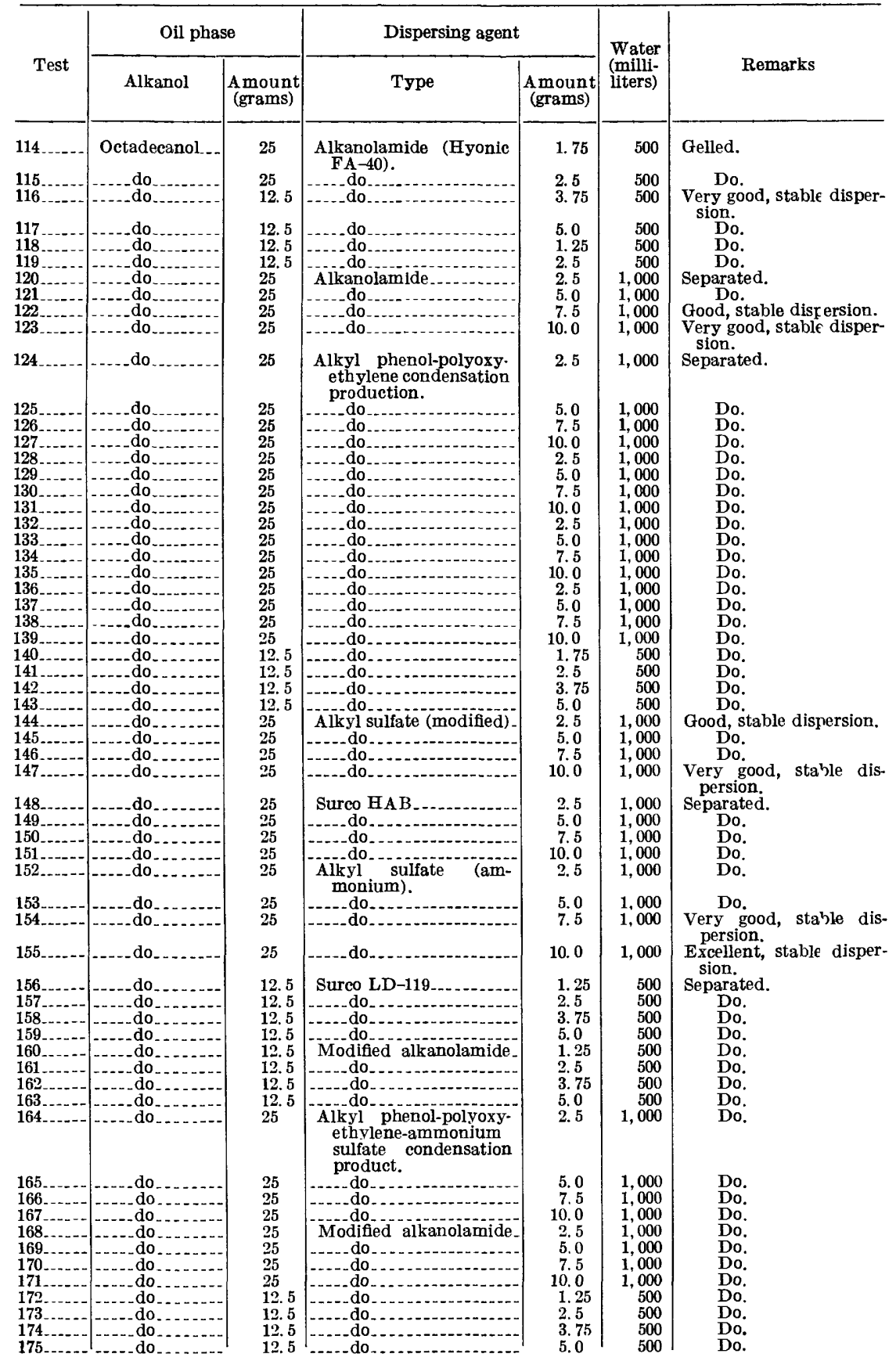


TABLE 3.-Oil-in-water dispersions of alkanols-Continued

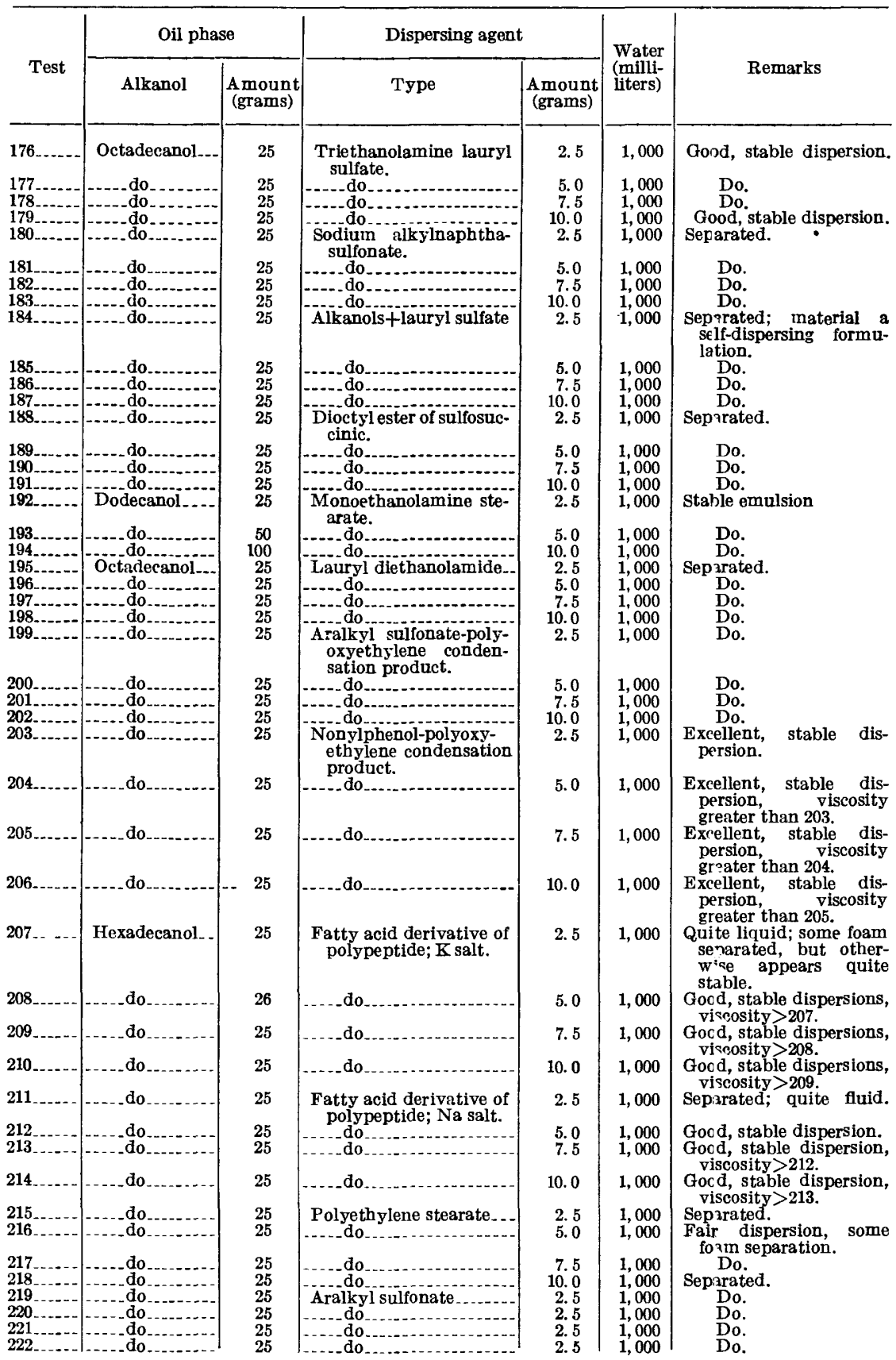


TABLES

TABLE 3.-Oil-in-water dispersions of alkanols-Continued

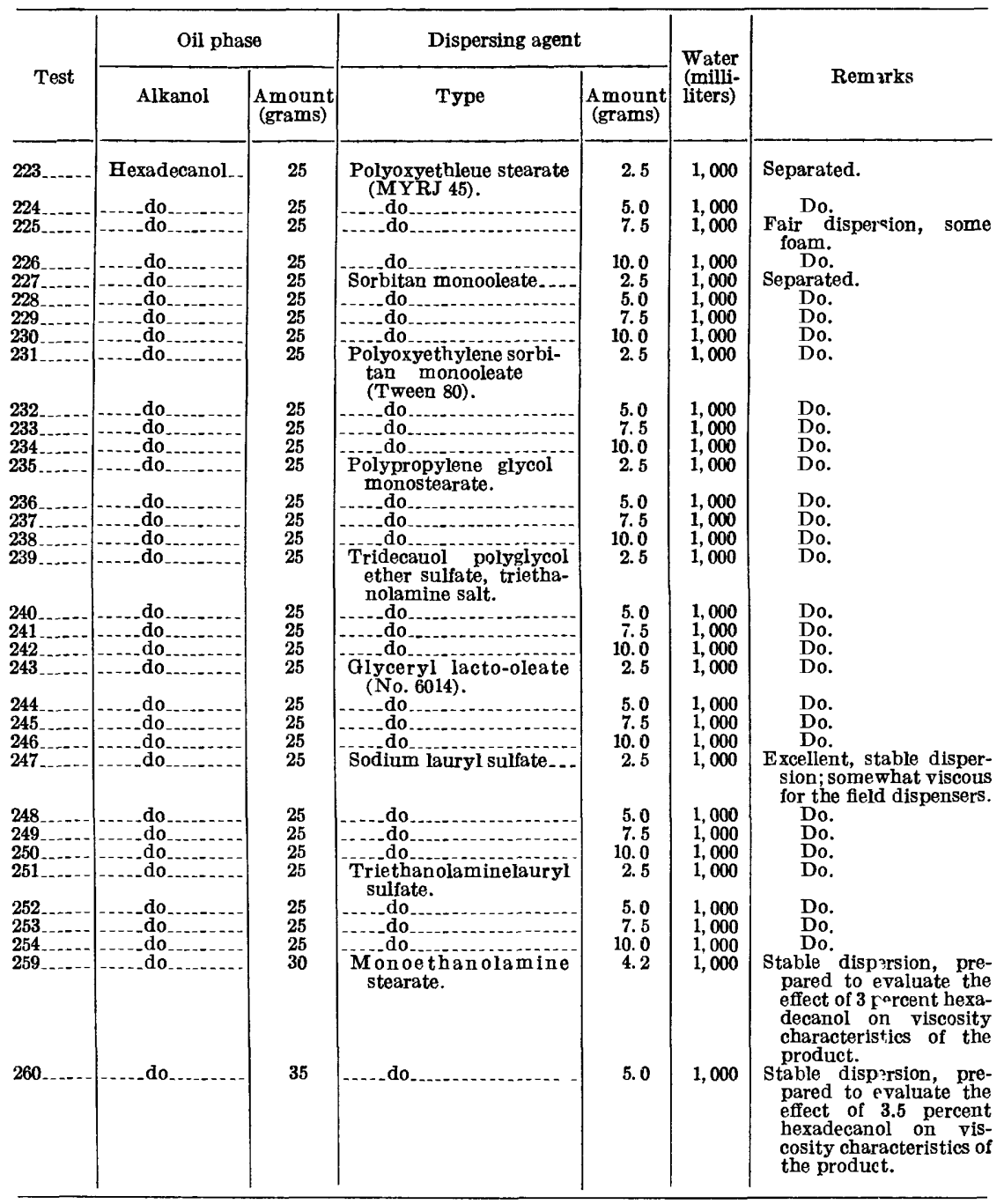


TABLE 4.-Water-in-oil dispersions of hexadecanol and octadecanol

\begin{tabular}{|c|c|c|c|c|c|c|c|}
\hline \multirow{2}{*}{ Test } & \multicolumn{2}{|c|}{ Oil phase } & \multicolumn{2}{|l|}{ Dispersing agent } & \multirow{2}{*}{$\begin{array}{l}\text { Water } \\
\text { (milli- } \\
\text { liters) }\end{array}$} & \multirow{2}{*}{$\begin{array}{l}\text { Spread- } \\
\text { ing rate }\end{array}$} & \multirow{2}{*}{ Remarks } \\
\hline & Alkanol & $\underset{\text { (grams) }}{\text { Amount }}$ & Type & $\underset{\text { (grams) }}{\text { Amount }}$ & & & \\
\hline $255 \ldots$ & Hexadecanol. & 100 & Sorbitan mono- & 10 & 100 & Poor...- & Stiff, heterogeneous \\
\hline $256 \ldots$ & ...... do... & 100 & $\begin{array}{l}\text { stearate. } \\
\text { Sorbitan oleate }\end{array}$ & 10 & 100 & do. & $\begin{array}{l}\text { parte. } \\
\text { Stiff. heterogeneous } \\
\text { parte, poorer than } \\
255 \text {. }\end{array}$ \\
\hline $257 \ldots$ & ..... do & 100 & Sorbitan monolaurate & 10 & 100 & $\ldots$ do & $\begin{array}{l}\text { Past ; better texture } \\
\text { an } 7 \text { appearance }\end{array}$ \\
\hline $261 \ldots$ & do & 100 & $\begin{array}{l}\text { Glyceryl mono- } \\
\text { stearate, self- } \\
\text { emulsifying. }\end{array}$ & 10 & 200 & ....do_... & $\begin{array}{l}\text { Pasta, fairly good } \\
\text { texture and } \\
\text { apnearance; better } \\
\text { thin } 257 . \\
\text { Past?; not as stiff }\end{array}$ \\
\hline 262 & - do do & $\begin{array}{l}100 \\
100\end{array}$ & _...do do do & $\begin{array}{l}10 \\
10\end{array}$ & $\begin{array}{l}300 \\
500\end{array}$ & Fair .... & $\begin{array}{l}\text { Past }{ }^{\circ} \text {; similar to } 261 . \\
\text { Thin paste; less }\end{array}$ \\
\hline $264 \ldots$ & .... do... & 100 & do & 10 & 1,000 & Good... & Liqe id; similar to \\
\hline $265 \ldots$ & $\ldots$ do & 100 & Alkanolamide.......... & 10 & 1,000 & Fair...- & Thick, liquid dis- \\
\hline $266 \ldots$ & ..... do. & 100 & $\begin{array}{l}\text { Nonyl phenoxy poly- } \\
\text { oxyethylene con- }\end{array}$ & 10 & 1,000 & & $\begin{array}{l}\text { persion, } \\
\text { Separated quickly. }\end{array}$ \\
\hline $267 \ldots$ & -... do. & 100 & $\begin{array}{l}\text { densate. } \\
\text { Nonylphenol-poly- } \\
\text { oxyethylene con- } \\
\text { densate. }\end{array}$ & 10 & 1,000 & Good... & $\begin{array}{l}\text { Good liquid dis- } \\
\text { persion. Sepa- } \\
\text { rated somewhat } \\
\text { afier } 24 \text { hours } \\
\text { standing. }\end{array}$ \\
\hline $268 \ldots$ & .... do & 100 & $\begin{array}{l}\text { Glyceryl mono- } \\
\text { stearate, self- } \\
\text { emulsifying. }\end{array}$ & 10 & 1,000 & ... do .... & A rerun of 264 \\
\hline 269 & ..... do & 100 & Cetyl betaine. ........ & 10 & 1,000 & Fair & $\begin{array}{l}\text { Goo- dispersion; too } \\
\text { viseous for current } \\
\text { fifld dispensers. }\end{array}$ \\
\hline $270 \ldots$ & Octadecanol & 100 & Sorbitan sesquioleate & 10 & 1,000 & do. & $\begin{array}{l}\text { Good dispersion, but } \\
\text { somewaht gela- } \\
\text { tinous. }\end{array}$ \\
\hline $271 \ldots$ & ..... do. & 100 & Aralkyl sulfonate & 10 & 1,000 & do & Stał 'e dispersion. \\
\hline $272 \ldots$ & -... & 100 & $\begin{array}{l}\text { Sodium-N-methyl- } \\
\text { N-alkyl taurate. }\end{array}$ & 10 & 1,000 & Fairly & $\begin{array}{l}\text { Thirk, spongy, } \\
\text { stable dispersion. }\end{array}$ \\
\hline $273 \ldots$ & .... do & 100 & $\begin{array}{l}\text { Alkyl phenol-poly- } \\
\text { oxyethylene con- } \\
\text { densation product. }\end{array}$ & 10 & 1,000 & poor & Separated. \\
\hline $274 \ldots$ & . . _ do & 100 & $\begin{array}{l}\text { Ammonium alkyl } \\
\text { sulfate. }\end{array}$ & 10 & 1,000 & Fair...- & $\begin{array}{l}\text { Stal 'e dispersion; } \\
\text { some separation } \\
\text { arpeared immi- } \\
\text { nent just after } \\
\text { st'rring was } \\
\text { stopped. Stable } \\
\text { af } 24 \text { hours. }\end{array}$ \\
\hline $275 \ldots$ & .... do do....... & 100 & $\begin{array}{l}\text { Mono- and digly- } \\
\text { cerides of fatty acids } \\
\text { plus preservative } \\
\text { and antioxidant. } \\
\text { N-coco-amino butyric }\end{array}$ & 10 & 1,000 & $\ldots$ do .... & $\begin{array}{l}\text { See remarks, } 274 \\
\text { ak ove. } \\
\text { Separated. }\end{array}$ \\
\hline $\begin{array}{l}277- \\
278-\end{array}$ & - & $\begin{array}{l}100 \\
100\end{array}$ & $\begin{array}{l}\text { Glyceryl lacto-oleate- } \\
\text { Polyoxyethylene sor- }\end{array}$ & $\begin{array}{l}10 \\
10\end{array}$ & $\begin{array}{l}1,000 \\
1,000\end{array}$ & & $\begin{array}{l}\text { Do. } \\
\text { Do. }\end{array}$ \\
\hline 279 & ..... do & 100 & $\begin{array}{l}\text { bitan beeswax } \\
\text { derivative. } \\
\text { Polyoxyethylene }\end{array}$ & 10 & 1,000 & & Do. \\
\hline $280 \ldots$ & .....do.. & 100 & $\begin{array}{l}\text { stearate. } \\
\text { Sorbitan monooleate. }\end{array}$ & 10 & 1,000 & Fair & Thick, stable dis- \\
\hline $281 \ldots$ & -.... do & 100 & Sorbitan mono- & 10 & 1,000 & $\ldots$...... & $\begin{array}{l}\text { persion. } \\
\text { Do. }\end{array}$ \\
\hline $282 \ldots$ & Hexadecanol. & 180 & $\begin{array}{l}\text { stearate. } \\
\text { Glyceryl mono- } \\
\text { stearate, self- } \\
\text { enulsifying. }\end{array}$ & 18 & 1,800 & & $\begin{array}{l}\text { Special preparation } \\
\text { fo" preliminary } \\
\text { field evaluation. }\end{array}$ \\
\hline $283 \ldots$ & . & 100 & $\begin{array}{l}\text { Sorbitan sesquioleate } \\
\text { plus } 10 \mathrm{gm} \text { cellulose } \\
\text { gum. }\end{array}$ & 10 & 1,000 & Fair.... & $\begin{array}{l}\text { Thick, spongy dis- } \\
\text { persion. Prepared } \\
\text { to evaluate the } \\
\text { "snonge" type } \\
\text { formulation. }\end{array}$ \\
\hline
\end{tabular}


TABLES

TABLE 4.-Water-in-oil dispersions of hexadecanol and octadecanol-Continued

\begin{tabular}{|c|c|c|c|c|c|c|c|}
\hline \multirow{2}{*}{ Test } & \multicolumn{2}{|c|}{ Oil phase } & \multicolumn{2}{|c|}{ Dispersing agent } & \multirow{2}{*}{$\begin{array}{l}\text { Water } \\
\text { (milli- } \\
\text { liters) }\end{array}$} & \multirow{2}{*}{$\begin{array}{l}\text { Spread- } \\
\text { ing rate }\end{array}$} & \multirow{2}{*}{ Remarks } \\
\hline & Alkanol & $\underset{\text { (grams) }}{\text { Amount }}$ & Type & $\begin{array}{c}\text { Amount } \\
\text { (grams) }\end{array}$ & & & \\
\hline $284 \ldots$ & Hexadecanol_. & 100 & $\begin{array}{l}\text { Sodium-N-methyl-N- } \\
\text { alkyl plus } 10 \mathrm{~g} \\
\text { cellulose gum. }\end{array}$ & 10 & 1,000 & -..do.... & $\begin{array}{l}\text { Thick, spongy dis- } \\
\text { persion. Prepared } \\
\text { to evaliate the } \\
\text { "spong?" type } \\
\text { formulation. }\end{array}$ \\
\hline $\begin{array}{l}285 \\
305\end{array}$ & Octadecanol.. & $\begin{array}{l}100 \\
100\end{array}$ & N-cetyl-N-ethyl mor- & $\begin{array}{l}10 \\
10\end{array}$ & 1,000 & $\begin{array}{l}\text { Fair } \\
\text { Fairly }\end{array}$ & $\begin{array}{l}\text { Do. } \\
\text { Stable, but nearly }\end{array}$ \\
\hline $306 \ldots$ & ....do... & 100 & $\begin{array}{l}\text { pholinium ethosul- } \\
\text { fate. } \\
\text { Polyoxyethylated }\end{array}$ & 10 & 1,000 & poor. & solid dispersion. \\
\hline 300 & - & 100 & $\begin{array}{l}\text { Polyoxyetnylated } \\
\text { fatty acid. }\end{array}$ & 10 & 1,000 & & separater. \\
\hline $307 \ldots$ & -..-do.. & 100 & $\begin{array}{l}\text { Polyoxyethylated } \\
\text { vegetable oil. }\end{array}$ & 10 & 1,000 & & Do. \\
\hline 308_.-. & -...do do & 100 & Polyoxyethylated & 10 & 1,000 & & Do. \\
\hline 309 & ......... & 100 & $\begin{array}{l}\text { Polyoxyethylated } \\
\text { fatty alkanol. }\end{array}$ & 10 & 1,000 & Fair & $\begin{array}{l}\text { Stable, but very vis- } \\
\text { cous dispersion. } \\
\text { Would not flow } \\
\text { througl dispensers. }\end{array}$ \\
\hline
\end{tabular}

TABLE 5.-Dispersions containing 11 to 20 percent octadecanol (Lorol 28) based on water, and using glyceryl monostearate (self-emulsifying) as the dispersing agent

\begin{tabular}{|c|c|c|c|}
\hline Test & $\begin{array}{l}\text { Octadecanol } \\
\text { (Lorol 28) } \\
\text { (grams) }\end{array}$ & $\begin{array}{c}\text { Glyceryl } \\
\text { monostearate } \\
\text { (Arlacel 165) } \\
\text { (grams) }\end{array}$ & Remarks \\
\hline 295. & 110 & 11 & Stable; slight foam; viscosity satisfactory. \\
\hline 296 & 120 & 12 & Stable; some foam; viscosity satisfactory. \\
\hline 297 & 130 & $\overline{13}$ & $\begin{array}{l}\text { Stable; some foam (greater than 296); viscosity satisfac- } \\
\text { tory. }\end{array}$ \\
\hline 298 & 140 & 14 & Stable; slight foam, viscosity satisfactory. \\
\hline 299 & 150 & 15 & Stable; slight foam; viscosity satisfactory. \\
\hline 300 & 160 & 16 & Stable; foam nil; viscosity satisfactory. \\
\hline 301 & 170 & 17 & $\begin{array}{l}\text { Stable; slight foam; viscosity satisfactory, but greater } \\
\text { than } 300 \text {. }\end{array}$ \\
\hline 302. & 180 & 18 & Stable; no foam; viscosity about the same as 301. \\
\hline 303 & 190 & 19 & Stable; no foam; viscosity greater than 302. \\
\hline 304 & 200 & 20 & Stable; no foam; viscosity greater than 303 . \\
\hline
\end{tabular}

TABLE 6.-Dispersions of octadecanol containing varying amounts of glyceryl monosterate (self-emulsifying) as the dispersing agent

\begin{tabular}{|c|c|c|}
\hline Test No. & $\begin{array}{c}\text { Glyceryl monostea- } \\
\text { rate (Arlacel 165) } \\
\text { (grams) }\end{array}$ & Remarks \\
\hline $\begin{array}{l}286 \\
287 \\
288 \\
289 \\
290 \\
291\end{array}$ & $\begin{array}{l}10 \\
11 \\
12 \\
13 \\
14 \\
15\end{array}$ & $\begin{array}{l}\text { Stable, foamy. } \\
\text { Do. } \\
\text { Stable. } \\
\text { Do. } \\
\text { Do. } \\
\text { Do. }\end{array}$ \\
\hline
\end{tabular}




\section{INDEX}

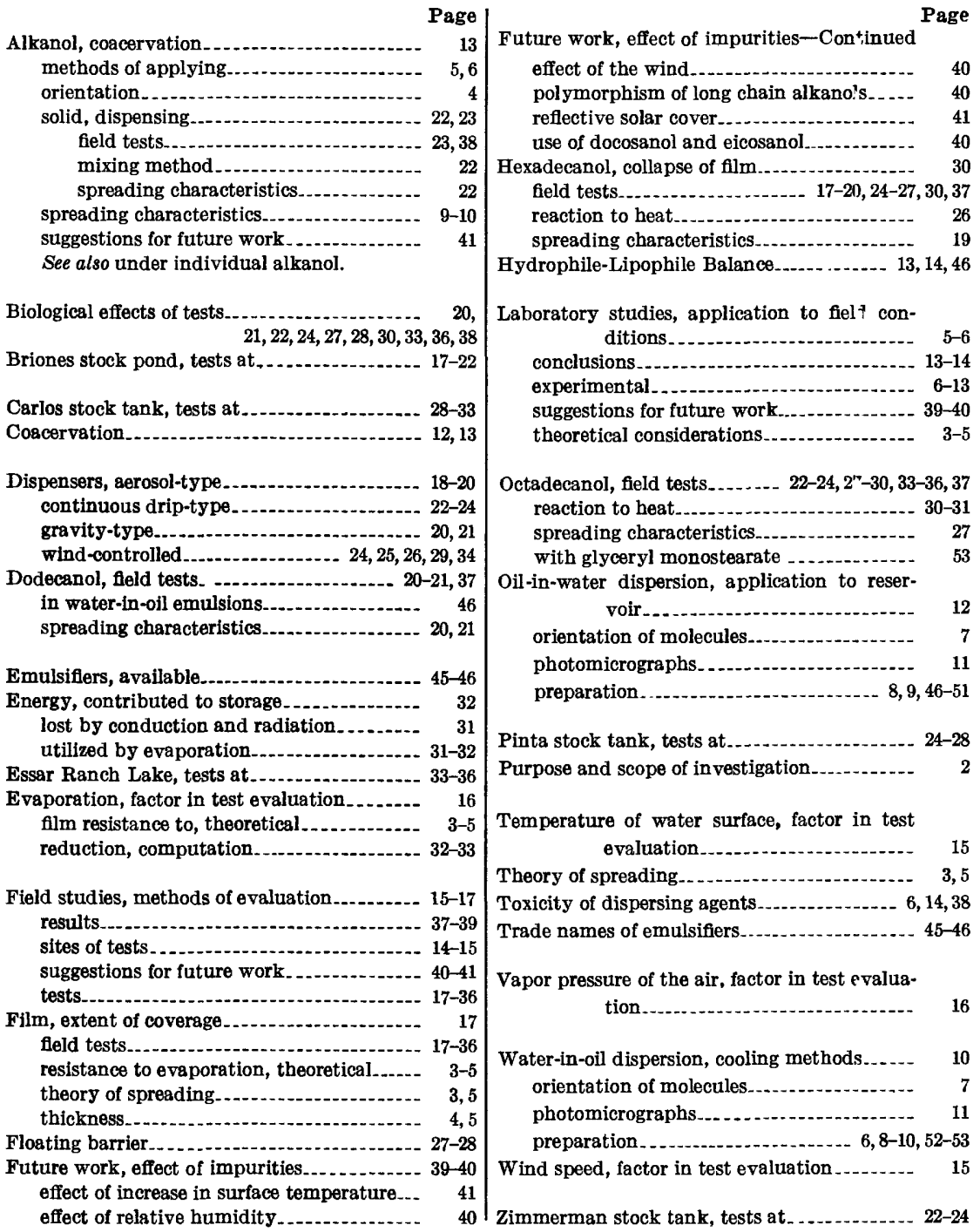

